\title{
ARTICLE
}

\section{Deltex1 antagonizes HIF-1 $\alpha$ and sustains the stability of regulatory T cells in vivo}

Huey-Wen Hsiao ${ }^{1, \star}$, Tzu-Sheng Hsu ${ }^{1,2,}$, Wen-Hsien Liu', Wan-Chen Hsieh', Ting-Fang Chou', Yu-Jung $\mathrm{Wu}^{1,2}$, Si-Tse Jiang ${ }^{3} \&$ Ming-Zong Lai, ${ }^{1,2}$

Application of regulatory T cells (Tregs) in transplantation, autoimmunity and allergy has been extensively explored, but how Foxp3 and Treg stability is regulated in vivo is incompletely understood. Here, we identify a requirement for Deltex1 (DTX1), a contributor to T-cell anergy and Foxp3 protein level maintenance in vivo. Dtx1 ${ }^{-/-}$Tregs are as effective as WT Tregs in the inhibition of $\mathrm{CD} 4{ }^{+} \mathrm{CD} 25^{-} \mathrm{T}$-cell activation in vitro. However, the suppressive ability of $D t \times 1^{-/-}$Tregs is greatly impaired in vivo. We find that Foxp3 expression is diminished when $D t \times 1^{-/}-$Tregs are co-transferred with effector Tcells in vivo. DTX1 promotes the degradation of HIF-1 $\alpha$. Knockout of HIF-1 $\alpha$ restores the Foxp3 stability and rescues the defective suppressive activity in Dtx $1^{-/-}$Treg cells in vivo. Our results suggest that DTX1 exerts another level of control on Treg stability in vivo by sustaining the expression of Foxp3 protein in Tregs.

\footnotetext{
${ }^{1}$ Institute of Molecular Biology, Academia Sinica, Taipei 11529, Taiwan, R.O.C. ${ }^{2}$ Graduate Institute of Immunology, National Taiwan University, Taipei 10057 Taiwan, R.O.C. ${ }^{3}$ National Laboratory Animal Center, National Applied Research Laboratories, Tainan 74147, Taiwan, R.O.C. * These authors contributed equally to this work. Correspondence and requests for materials should be addressed to M.-Z.L. (email: mblai@gate.sinica.edu.tw).
} 
C $\mathrm{D} 4{ }^{+} \mathrm{CD} 25^{+}$regulatory $\mathrm{T}$ cells (Tregs) maintain $\mathrm{T}$-cell tolerance and prevent autoimmune diseases by inhibiting T-cell activation ${ }^{1-5}$. The suppressive action of Tregs is known to proceed via many mechanisms, including cytolysis, secretion of suppressive cytokines, competition for cytokines, metabolic disruption of targeted cells and priming of dendritic cells $^{3,6,7}$. Several Treg surface molecules, such as CTLA4, GITR, CD103, LAG3 and FR4, are also involved in the inhibition of target $\mathrm{T}$-cell activation through cell-cell contact ${ }^{8-10}$. Tregs are classified into thymus-derived $\mathrm{CD}^{+}{ }^{+} \mathrm{CD} 25^{+}$Foxp $3{ }^{+}$Tregs (tTregs), which develop in the thymus before their exit into the peripheral circulation, and induced Tregs (iTregs or converted Tregs), which may be generated by treatment with transforming growth factor (TGF)- $\beta$ and interleukin (IL)-2 (refs 11,12). Tregs are marked by the expression of Foxp3, a forkhead family transcription factor that is essential for their development and function ${ }^{13,14}$. In addition, the persistent presence of Foxp 3 is required to maintain the effector activities of Tregs ${ }^{15,16}$. The expression and epigenetic control of Foxp3 gene have been well characterized ${ }^{17}$. In contrast, regulation on the protein stability of Foxp3 remains poorly understood.

The potential application of Tregs in transplantation, autoimmune diseases and allergy are being extensively examined ${ }^{18-21}$. How Foxp3 and Treg stability are regulated in vivo remains incompletely understood. Different results are reported for the in vivo Treg stability ${ }^{22}$. Treg cells have been shown to be relatively stable in vivo, with a small population of Tregs susceptible to loss of Foxp3 (refs 23,24). Alternatively, pathogen infection or inflammatory cytokines destabilize Foxp 3 protein and decrease the Treg population ${ }^{25-28}$. Loss of Foxp3 in Tregs results in pathogenic autoimmunity manifested by the generation of inflammatory effector $\mathrm{T}$ cells ${ }^{29,30}$. Foxp3 protein is subjected to controlled degradation by several molecules. E3 ubiquitin ligase Stub1 induces the K48-polyubiquitination and degradation of Foxp3 (ref. 28), whereas deubiquitinase USP7 decreases Foxp3 polyubiquitination and increases Foxp 3 expression ${ }^{31}$. Hypoxiainducible factor- $1 \alpha$ (HIF- $1 \alpha)$ binds Foxp3, inducing its degradation and thereby inhibiting Treg development ${ }^{32}$. Interfering with the binding of HIF- $1 \alpha$ to Foxp3 increases Foxp 3 protein stability and Treg suppressive activity ${ }^{33}$. Given the hypoxic conditions in vivo ${ }^{34}$, a mechanism should exist to prevent Foxp3 protein from HIF-1 $\alpha$-mediated destabilization in vivo.

Deltex (DTX) is a ubiquitin E3 ligase containing N-terminal Notch-binding WWE domains, a proline-rich motif and a RING finger (RF) domain at the C-terminus ${ }^{35,36}$. DTX mediates Notch activation in Drosophila ${ }^{37,38}$, but its exact role in Notch signalling in vertebrates remains unclear. We recently found that DTX1 negatively regulates T-cell activation by targeting MAP kinase kinase kinase 1 (MEKK1) for degradation ${ }^{39}$. DTX1 is a transcriptional target of nuclear factor of activated T cell (NFAT), is induced in T-cell anergy and inhibits T-cell activation in E3-dependent and E3-independent mechanisms ${ }^{40}$. DTX1-deficiency impairs T-cell anergy induction, promotes excess T-cell activation and generates autoimmunity ${ }^{40}$. In this study, we found that Treg-specific knockout of Dtx1 also led to enhanced T-cell activation and autoantibody generation. Surprisingly, DTX1 deficiency did not affect the expression of Foxp3, nor was the suppressive activity of Treg affected in vitro. The in vivo suppressive function of Treg cells was largely impaired in the absence of DTX1, which was attributed to a diminished Foxp3 protein stability in Dtx $1^{-/}$- Tregs in vivo. We found that Foxp3 protein stability was enhanced by DTX1, and DTX1 induced degradation of HIF- $1 \alpha$ and interfered with the capacity of HIF- $1 \alpha$ to degrade Foxp3. Knockout of HIF-1 $\alpha$ restored the Foxp3 expression and rescued the defective suppressive activity in Dtx $1^{-/-}$
Treg cells in vivo. Our results illustrate a novel role for DTX1 in maintaining the protein stability of Foxp3 in vivo and reveal an additional level of control of Treg stability.

\section{Results}

Treg-specific deletion of Dtxl enhances T-cell activation. We previously demonstrated that $\mathrm{T}$ cell-specific deletion of Dtx1 $\left(D+x 1^{f / f} C d 4^{C r e}\right.$ ) leads to enhanced T-cell activation and autoantibody formation ${ }^{40}$. To examine the possible involvement of DTX1 in regulatory T-cell function, we generated mice with Treg-specific deletion of Dtx 1 by crossing Dtx $1^{f / f}$ mice with Foxp $3^{G F P-C r e}$ mice ${ }^{41}$ or Foxp $3^{R F P-C r e}$ mice produced in this study. Treg cells were marked by green fluorescent protein (GFP) or red fluorescent protein (RFP) expression. No difference was found between Foxp $3^{G F P-C r e}$ mice and Foxp $3^{R F P-C r e}$ mice, and Foxp $3^{C r e}$ was used to represent both. The selective deficiency of DTX1 in Foxp $3^{+} \mathrm{T}$ cells (tTregs), but not in Foxp $3^{-} \mathrm{T}$ cells from Foxp $3^{C r e} D t x f^{f / f}$ mice, was confirmed by immunoblots (Supplementary Fig. 1a). Similar to mice with systemic and T cell-specific conditional knockout of Dtx1 (ref. 40) thymic development was not disturbed by deficiency of DTX1 in Tregs (Supplementary Fig. 1b). Populations of splenic $\mathrm{CD}^{+}$and $\mathrm{CD}^{+} \mathrm{T}$ cells were comparable between control and Foxp $3^{C r e}$ Dt $x 1^{f / f}$ mice (Supplementary Fig. 1c). Neither was the naïve and memory $\mathrm{T}$-cell ratio affected by Treg-specific absence of DTX1 (Supplementary Fig. 1d). However, T-cell proliferation and IL-2 production were elevated in T cells from Foxp $3^{C r e} D t x 1^{f / f}$ mice, relative to $\mathrm{T}$ cells from Foxp $3^{C r e}$ mice (Fig. 1a,b). Small
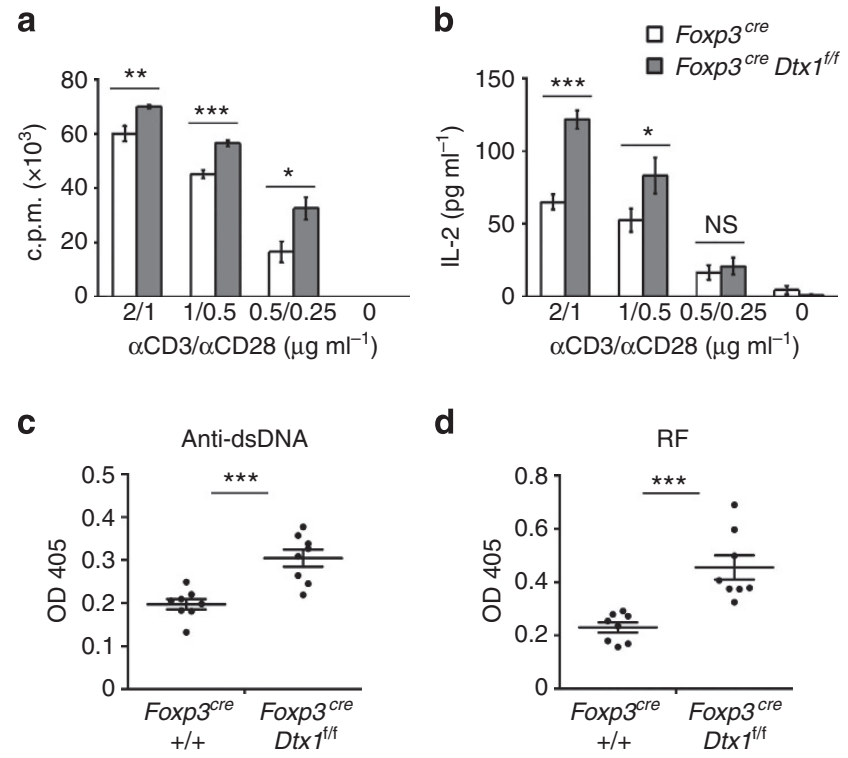

Figure 1 | Conditional DTX1 deficiency in Tregs leads to enhanced T-cell activation and elevated autoantibody generation. (a,b) Treg-specific deletion of Dtx 1 resulted in enhanced T-cell activation. Lymph node T cells from control (Foxp3 ${ }^{\mathrm{Cre}}$ ) or Foxp3 ${ }^{\mathrm{Cre}} \mathrm{Dtx} \mathrm{f}^{\mathrm{f} / \mathrm{f}}$ mice were stimulated with plate-bound anti-CD3 plus anti-CD28. T-cell proliferation (a) was determined by $\left[{ }^{3} \mathrm{H}\right]$ thymidine incorporation $56 \mathrm{~h}$ after stimulation, and IL-2 production (b) was measured $40 \mathrm{~h}$ after activation. Error bars represent s.d. Data are mean \pm s.d. of triplicate samples from one mouse pair. Results were independently reproduced in five mouse pairs. (c,d) Elevated serum anti-DNA antibodies and rheumatoid factor in Foxp3 ${ }^{\mathrm{Cre}} \mathrm{Dtx} \mathrm{f}^{\mathrm{f} / \mathrm{f}}$ mice. Sera (1:100 dilution) from Foxp3 ${ }^{\mathrm{Cre}} \mathrm{Dtx} \mathrm{f}^{\mathrm{f} / \mathrm{f}}$ mice and Foxp3 $3^{\mathrm{Cre}}$ controls older than 6 months were analysed by anti-dsDNA (c) and anti-lgG1 (d) antibodies. $n=8 .{ }^{\star} P<0.05 ;{ }^{\star \star} P<0.01 ;{ }^{\star \star \star} P<0.001$ (two-tailed unpaired $t$-test). 
increases in interferon (IFN) $-\gamma$ and IL-17 expression could be detected in naïve Foxp $3^{C r e} D t x 1^{f / f}$ T cells (Supplementary Fig. 1e). In addition, elevation of anti-dsDNA antibodies and rheumatoid factor (anti-IgG1) was also found in older Foxp $3^{C r e} D t x 1^{f / f}$ mice (>6-month old; Fig. 1c,d). Notably, the increase in T-cell activation in Foxp3 ${ }^{C r e}$ Dtxiff $\mathrm{f}$ cells was less profound than in $\mathrm{T}$ cells from $C d 4^{C r e} D t x 1^{f / f}$ mice ${ }^{40}$. No increase in anti-histone antibodies was found in Foxp $3^{\mathrm{Cre}} \mathrm{Dtx} 1^{\mathrm{f} / f}$ mice (Supplementary Fig. 1f), in contrast to that seen in $C d 4^{C r e} D t x 1^{f / f}$ mice ${ }^{40}$. These results suggest that DTX1-deficiency in Treg accounts for part, but not all, of the phenotypes observed in $C d 4^{C r e} D t \times 1^{f / f}$ mice, and DTX1 is required for the functional activities of Treg in vivo.

Dtx1 ${ }^{-/}$tTregs fail to suppress inflammatory bowel disease. The observations that Treg-conditional knockout of DTX1 led to enhanced T-cell activation and autoantibody production were unexpected, because we have previously found that DTX1 deficiency did not affect the development of tTreg ${ }^{40}$, and the frequency of $\mathrm{CD}^{+}{ }^{+}$Foxp $3^{+}$cells in thymus, spleen and lymph node was comparable between Dtx $1^{-/}$mice and littermate control (wild-type (WT)) animals (Fig. 2a). The production of IL-10 and TGF- $\beta$ in Dtx $1^{-/-}$tTreg cells was indistinguishable from that in WT tTreg (Fig. 2b,c). We also determined the expression of several Treg-associated molecules in isolated WT and Dt $x 1^{-1-}$ tTreg cells; CTLA-4, GITR, FR4, LAG3, CD103, ICOS and surface TGF- $\beta$ expression were all comparable between WT and Dtx $1^{-/-}$tTreg cells (Fig. 2d and Supplementary Fig. 2a,b). Furthermore, in an in vitro suppression analysis, Dt $x 1^{-/}$tTreg cells were as effective as Tregs from WT littermate controls in suppressing the proliferation of $\mathrm{T}$-cell antigen receptor (TCR)-stimulated $\mathrm{CD} 4{ }^{+} \mathrm{CD} 25^{-} \mathrm{T}$ cells in proportion to the number of tTreg cells added (Fig. 2e). Recent studies have also revealed differences between polyclonal and monoclonal Treg populations in the suppression mechanism ${ }^{5}$. We examined antigen-specific Treg suppression, and found no difference between OT-2 Tregs and OT-2/Dtx1 ${ }^{-/-}$Tregs in the inhibition of OT-2 effector T cells (Fig. $2 \mathrm{f}$ ).

However, in an in vivo functional assay, Dtx $1^{-/-}$tTregs displayed a diminished capacity to suppress T-cell activation. Colitis was induced in Rag1 $^{-/-}$mice by administration of $\mathrm{CD} 4{ }^{+} \mathrm{CD} 25^{-} \mathrm{T}$ cells, leading to $20-30 \%$ weight loss, rectal prolapse and diarrhoea (Fig. 2g,h). Tissue sections of inflamed colon revealed inflammatory infiltrate, epithelial hyperplasia, crypt cell damage and goblet cell damage (Fig. 2i). Co-injection with WT tTregs effectively repressed the induction of colitis by $\mathrm{CD} 4{ }^{+} \mathrm{CD} 25^{-} \mathrm{T}$ cells. In contrast, the co-administration of $D t \times 1^{-/}$tTregs only weakly reduced the colitis-associated pathogenesis (Fig. 2g-i), suggesting that the absence of DTX1 greatly diminished the suppressive activities of tTregs in vivo. Therefore, even though the expression of DTX1 is dissociated from the development and in vitro activities of tTregs, DTX1 is indispensable for the in vivo function of tTregs.

Dtx1 ${ }^{-/-}$iTreg cells fail to inhibit allergic inflammation. In addition to tTregs, Tregs could be generated from CD4 ${ }^{+} \mathrm{CD} 25^{-}$ $\mathrm{T}$ cells by incubation with anti-CD3/anti-CD28 and TGF- $\beta$. Both DTX1 and Foxp3 were induced in $\mathrm{CD} 4{ }^{+} \mathrm{CD} 25^{-} \mathrm{T}$ cells treated with anti-CD3/anti-CD28 in the presence of TGF- $\beta$, with an earlier peak in upregulation of DTX1 than Foxp3 during iTreg differentiation (Fig. 3a). Despite that DTX1 was induced before Foxp3 in iTregs, the absence of DTX1 did not affect generation of iTregs from CD $4{ }^{+} \mathrm{CD} 25^{-} \mathrm{T}$ cells. During the differentiation of iTregs, the induction of Foxp3 was nearly identical between WT and Dt $x 1^{-/-}$T cells (Fig. 3b). Together with the fact that Foxp3 levels were comparable between WT and Dtx1 $1^{-/-}$tTregs (Fig. 2), it is clear that DTX1 does not regulate the expression of
Foxp3 during the development of Tregs in the thymus or periphery. In addition, no differences in the expression of CTLA-4, GITR, FR4 or LAG3 could be found between WT and Dtx $1^{-1-}$ iTreg cells (Fig. 3c). We also analysed the in vitro suppressive activity of iTregs. Both WT iTregs and DTX1-KO iTregs inhibited the activation of $\mathrm{CD} 4{ }^{+} \mathrm{CD} 25^{-} \mathrm{T}$ cells to the same extent (Fig. 3d). Similar to tTregs, DTX1 deficiency did not affect the suppressive function of iTregs in vitro.

We further examined the in vivo regulatory function of iTregs. Lung inflammation was examined by bronchoalveolar lavage (BAL). Allergen-induced IL-4 secretion in BAL was suppressed by WT iTregs but was less effectively inhibited by Dt $x 1^{-/}$iTregs (Fig. 3e). WT iTregs inhibited ovalbumin (OVA)-mediated secretion of IL-5, IL-6 and IL-13 in BAL, whereas Dt $x 1^{-/-}$iTregs failed to prevent the production of these cytokines. OVA sensitization also led to massive inflammatory cell infiltration and mucus obstruction of the airway upon OVA re-challenge (Fig. 3f). Pre-administration of WT iTregs prevented this exacerbation of the allergic response (Fig. 3f, OVA + WT iTreg). In contrast, Dt $x 1^{-9}$ iTregs cells were unable to suppress the profound immune reaction triggered by allergen re-challenge (Fig. $3 \mathrm{f}, \mathrm{OVA}+D t \times 1^{-/-}$iTreg). These results illustrate that DTX1 is also required for the in vivo suppressive function of iTregs.

Downregulation of Foxp3 in transferred Dtx1 ${ }^{-/-}$tTreg cells. The prominent role of DTX1 in the in vivo Treg effector function prompted further search for possible defects in Dtx $1^{-/}$Treg cells. The expression of Foxo1, Foxo3a, Ikzf4 (encoding Eos), Ebi3 (encoding IL-35 subunit) and Gzmb (encoding granzyme B) was similar in tTreg cells from WT and DTX1-null mice (Supplementary Fig. 2c-e). We also examined whether the expression of chemokine receptors, required for $\mathrm{T}$-cell homing in vivo, was altered by DTX1 deficiency. The transcripts of Ccr4, Ccr6 and Ccr7, as well as the surface amounts of CCR4, CCR5, and CCR6, were nearly identical between WT and Dtx1-1tTreg cells isolated from spleen and mesentery lymph nodes (Supplementary Fig. 3). DTX1 deficiency thus did not affect the expression of several chemokine receptors on Treg cells. We also examined activation-induced cell death in WT and Dtx $1^{-/-}$ tTreg. No difference was found in the extent of cell death (Annexin- $\mathrm{V}^{+}$and $\mathrm{PI}^{+}$) induced by $\mathrm{CD} 3$ stimulation between these two types of tTregs (Supplementary Fig. 2f). Because the in vivo conditions for iTreg differentiation is not necessarily optimal, we additionally determined whether the conversion of $\mathrm{CD}^{+}$naïve $\mathrm{T}$ cells into iTreg cells at low TGF- $\beta$ concentration was specifically affected by DTX1 deficiency. Only a very small decease in Foxp3 levels was found in the generation of Dtx $1^{-/-}$ iTreg cells at suboptimal TGF- $\beta$ concentrations, relative to WT iTreg cells (Supplementary Fig. 4a).

Because iTregs may not be able to maintain stable Foxp3 expression in vivo ${ }^{42,43}$, tTregs were used for further investigation of in vivo stability. To examine the consequences of defective Dt $x 1^{-/-}$tTregs in vivo, WT or Dtx $1^{-/-}$tTreg cells were transferred into Rag1 ${ }^{-1-}$ mice, and the fraction of CD4 ${ }^{+} \mathrm{T}$ cells with Foxp3 expression in spleen and lymph nodes was determined 1 week after transfer. The recovered $\mathrm{CD} 4^{+}$Foxp $3^{\text {high }}$ population was similar for WT and Dtx $1^{-/-}$ tTregs (Fig. 4a). The $\mathrm{CD}^{+}$T-cell frequency repopulating different lymph tissues of Rag1 $1^{-1}$ mice was comparable after the transfer of WT and Dtx $1^{-/-}$tTregs (Fig. 4b). We then examined the effect of $\mathrm{CD} 4{ }^{+} \mathrm{CD} 25^{-}$T-cell co-transfer on the in vivo stability of tTregs. CD45.2 ${ }^{+}$tTregs were co-administered with $\mathrm{CD}_{45.1}+$ effector $\mathrm{T}$ cells into Rag1 ${ }^{-I}-$ mice. One week later, the CD $45.2^{+}$Foxp $3^{\text {high }}$ populations in spleen and lymph 
a

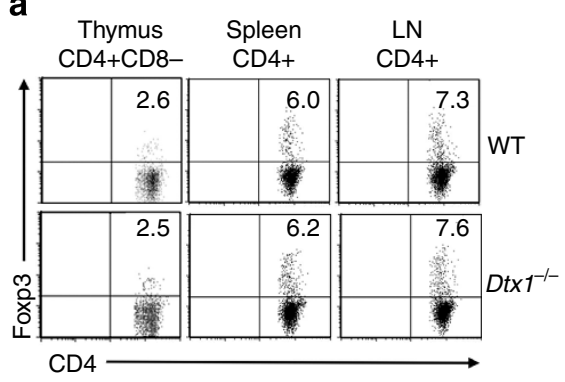

d

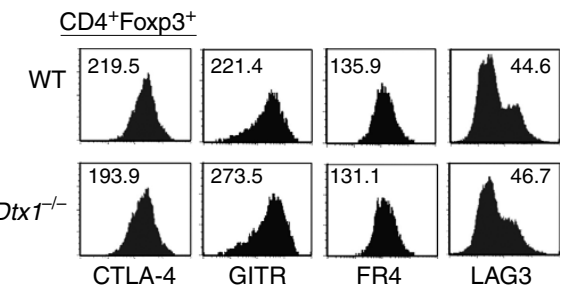

f

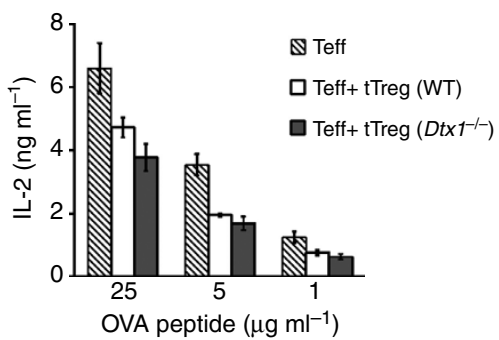

b

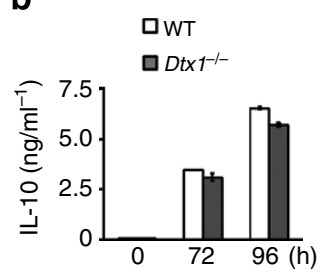

C

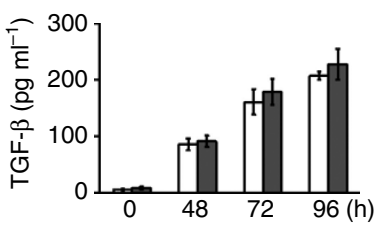

e

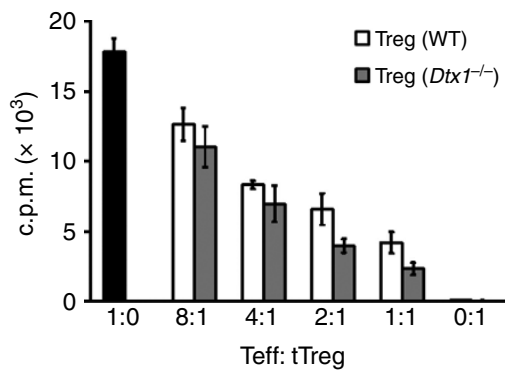

g

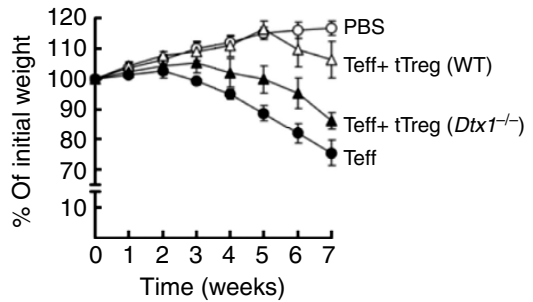

h

i
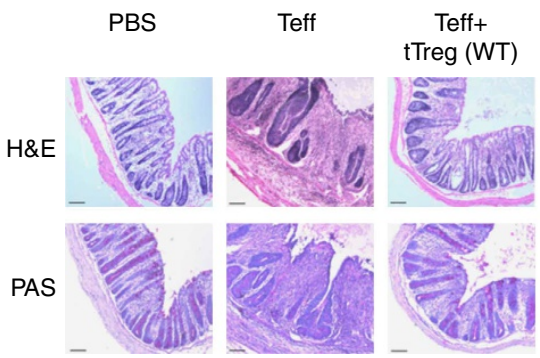

Teff+ $\operatorname{treg}\left(D t \times 1^{-1-}\right)$

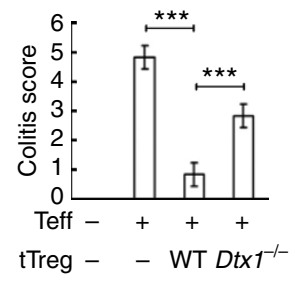

Figure 2 | DTX1 deficiency impairs the suppressive activity of tTregs in vivo. (a) Normal CD4 ${ }^{+}$Foxp3 $3^{+}$population in $D t \times 1^{-/-}$mice. $C D 4^{+} \mathrm{CD} 8{ }^{-}$or CD4 ${ }^{+}$population in thymocytes, splenocytes and lymph node cells were gated, and the fraction of Foxp3 ${ }^{+}$population determined by FACS. (b,c) Normal IL-10 and TGF- $\beta$ secretion in Dtx1 ${ }^{-/-}$tTreg cells. CD4 ${ }^{+}$CD25 $5^{+}$cells were stimulated with anti-CD3/CD28 plus IL-2, and the secretion of IL-10 (b) and TGF- $\beta$ (c) were determined by ELISA. (d) DTX1 deficiency does not affect Treg phenotype. The expression of CTLA-4, GITR, FR4 and LAG3 in WT and $D t \times 1^{-/-} \mathrm{CD} 4{ }^{+} \mathrm{CD} 25^{+}$cells were determined by flow cytometry. Number indicates mean fluorescence intensity. (e) Normal in vitro suppressive activity of Dtx $1^{-/-}$tTreg cells. Splenic CD4 ${ }^{+}$CD25 $5^{-}$cells $\left(1 \times 10^{5}\right)$ were incubated with anti-CD3 $\left(1 \mu \mathrm{g} \mathrm{ml} \mathrm{I}^{-1}\right), 3 \times 10^{5} \gamma$-irradiated T-depleted splenic cells and the indicated ratios of WT and Dtx $1^{-/-} \mathrm{CD} 4{ }^{+} \mathrm{CD} 25^{+}$tTreg cells. $\left[{ }^{3} \mathrm{H}\right]$ Thymidine incorporation was determined at $80 \mathrm{~h}$. Values are mean $\pm \mathrm{s}$.d. of triplicate samples in an experiment. (f) Normal antigen-specific suppression by Dtx $1^{-/}-$tTreg cells. tTreg cells $\left(2.5 \times 10^{4}\right)$ from OT-II transgenic mice (WT) or Dtx $1^{-/-} \times$OT-II mice were incubated with OT-II CD4 ${ }^{+} \mathrm{CD} 25^{-}$cells $\left(1 \times 10^{5}\right)$ in the presence of OVA and $\gamma$-irradiated T-depleted splenic cells. IL-2 production was measured $48 \mathrm{~h}$ later. Data shown are representative of five $(\mathbf{a}, \mathbf{e})$, three $(\mathbf{b}-\mathbf{d})$ or two (f) independent experiments. (g-i) Diminished inhibitory activity of Dtx $1^{-/-}$tTreg cells in vivo. CD4 ${ }^{+} \mathrm{CD} 25^{-}$T cells $\left(4 \times 10^{5}\right)$ or PBS were administered intraperitoneally into Rag $1^{-/-}$mice with or without $1 \times 10^{5}$ tTregs. Body weight ( $\mathbf{g}$ ) was assessed weekly for 7 weeks. (h) Colitis was determined at the end of 7 th week and scored as described in Methods. Data are the mean \pm s.d. of six mice in each group. ${ }^{\star \star \star} P<0.001$ (paired t-test). (i) Mice were killed and colons were removed, cleaned, fixed in paraformaldehyde, embedded in paraffin, sectioned and stained with haematoxylin and eosin (H\&E) and periodic acid-Schiff (PAS). Micrographs are representative of the six mice in each group. Scale bar, $100 \mu \mathrm{m}$.

nodes of the recipient mice were quantitated. A large percentage of WT tTreg cells retained high levels of Foxp3 expression when co-transferred with $\mathrm{CD} 4{ }^{+} \mathrm{CD} 25^{-} \mathrm{T}$ cells (Fig. 4c). In contrast, the Foxp $3^{\text {high }}$ population from mice receiving Dt $x 1^{-/-}$tTregs was profoundly reduced (Fig. 4c). In contrast to the stability of WT Tregs in vivo, DTX1 is required for the in vivo stability of Tregs when $\mathrm{T}$ effector cells were present. In addition, small increases in the expression of IFN- $\gamma$, IL-17, TNF- $\alpha$ and IL- 4 in the Dtx $1^{-/-}$tTreg cells recovered from Rag1 $1^{-1}$ mice were found (Supplementary Fig. 4b), suggesting that some portions of the tTreg population may be converted into effector cells in vivo. 
a

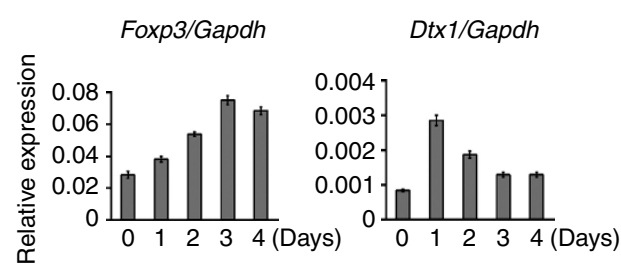

C

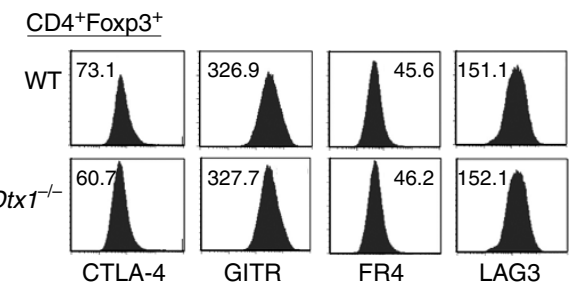

b

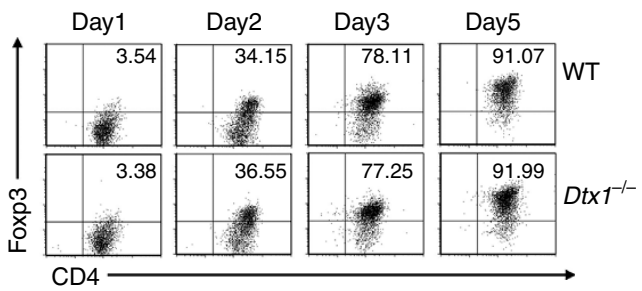

d

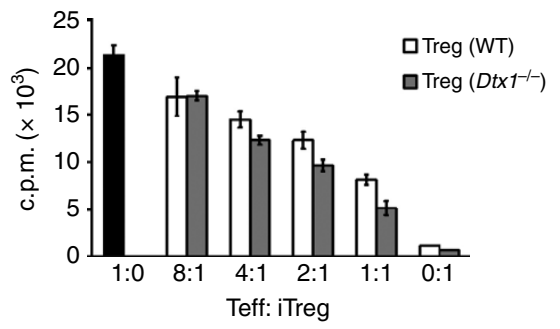

e

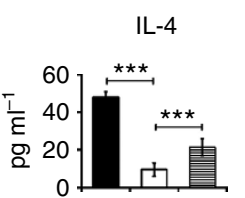

IL-6

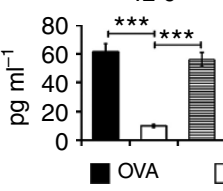

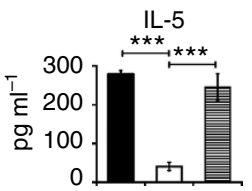

IL-13

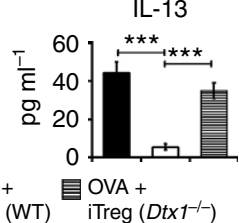

f

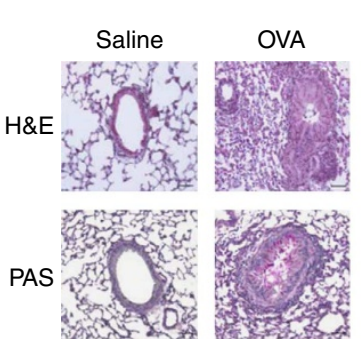

OVA +

OVA + iTreg (WT) iTreg $\left(D t x 1^{-/-}\right)$
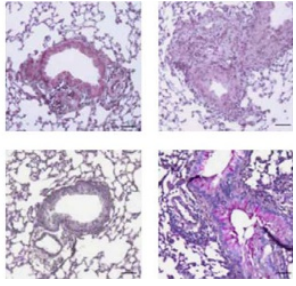

Figure $3 \mid$ Dtx1 ${ }^{-/-}$iTreg cells are functionally defective in vivo. (a) Induction of Dtx1 and Foxp3 during iTreg differentiation. CD4 ${ }^{+}$CD25 ${ }^{-}$T cells from WT mice were treated with immobilized anti-CD3/CD28 in the presence of TGF- $\beta\left(5 \mathrm{ng} \mathrm{ml}^{-1}\right)$ and IL-2 $\left(20 \mathrm{ng} \mathrm{ml}^{-1}\right)$ for 4 days, and the expression of the transcripts of Dtx1 and Foxp3 determined by quantitative PCR. $(\mathbf{b}, \mathbf{c})$ Differentiation of iTregs and expression of Foxp3 were not affected by DTX1 deficiency. $\mathrm{CD} 4^{+} \mathrm{CD} 25^{-}$T cells from WT and Dtx $1^{-/-}$mice were treated as in $\mathbf{a}$, and Foxp3 expression at days 1, 2, 3 and 5 was assessed by intracellular staining (b). The expression of CTLA-4, GITR, FR4 and LAG3 of iTregs at day 5 was determined (c). Numbers indicate mean fluorescence intensity. (d) Normal in vitro suppressive activity of $D t \times 1^{-/-}$iTreg cells. CD4 ${ }^{+} \mathrm{CD} 25^{-}$T cells from WT and Dtx $1^{-/-}$T cells were differentiated into iTregs for 5 days. Splenic $\mathrm{CD} 4{ }^{+} \mathrm{CD} 25^{-}$cells $\left(1 \times 10^{5}\right)$ were activated in the presence of the indicated ratio of $\mathrm{CD} 4{ }^{+} \mathrm{CD} 25^{+}$iTreg cells described in Fig. $2 \mathrm{e}$. $\left[{ }^{3} \mathrm{H}\right]$ thymidine incorporation was determined at $80 \mathrm{~h}$. Results are the mean $\pm \mathrm{s}$.d. of triplicate samples from a single experiment. Experiments were reproduced independently three times for $\mathbf{b}-\mathbf{d}$ and twice for $\mathbf{a}$. (e,f) Diminished in vivo inhibitory activity of Dtx $1^{-/-}$iTreg cells. C57/BL6 mice were treated with $\mathrm{CD} 4{ }^{+} \mathrm{CD} 25+$ iTreg cells or PBS on day 0 , and primed with $50 \mu \mathrm{g}$ ovalbumin (OVA) in alum on days 1 and 14 . Mice were challenged with aerosolized $1 \%$ OVA by airway from days 21 to 24. Mice were killed on day 25 and bronchoalveolar lavage was collected. The contents of IL-4, IL-5, IL-6 and IL-13 were determined by Cytometric Bead Array kit (e). Sections of lung were examined after staining with H\&E and PAS (f). ${ }^{\star \star \star} P<0.001$ (paired $t$-test).

Micrographs are representative of the six mice in each group. Scale bar, $50 \mu \mathrm{m}$.

DTX1 promotes HIF-1 $\alpha$ degradation. Because the in vivo stability of Foxp3 was compromised in the presence of co-transferred $\mathrm{CD} 4{ }^{+} \mathrm{CD} 25^{-} \mathrm{T}$ cells, we speculate that inflammation associated with effector T cells contributes to Foxp3 downregulation. We examined whether $D t x 1^{-/-}$Tregs behaved differently from WT Tregs in the inflammatory mucosal environments where colitis and allergic airway responses take place. Retinoic acid is known to promote the differentiation of Tregs in vivo at mucosal sites that are often hypoxic ${ }^{44,45}$. WT and Dtx $1^{-/-} \mathrm{CD}^{+} \mathrm{T}$ cells responded similar to retinoic acid in TGF- $\beta$-induced iTreg differentiation (Supplementary Fig. 5a). $D t \times 1^{-/-}$iTregs generated in the presence of retinoic acid produced IL-10 and TGF- $\beta$ indistinguishably from WT iTregs (Supplementary Fig. 5b) and suppressed the activation of effector $\mathrm{T}$ cells similar to retinoic acid-treated WT iTregs, as measured by the secretion of IFN- $\gamma$ and IL-2 by effector $\mathrm{T}$ cells (Supplementary Fig. 5c). DTX1 deficiency thus did not affect the ability of retinoic acid to stabilize the Treg population.
Recent studies demonstrate that Foxp3 protein could be destabilized by incubation with inflammatory cytokines in vitro ${ }^{25-28}$. We examined whether DTX1 regulated the stability of Foxp3 in Treg cells encountering inflammatory cytokines. WT and Dtx $1^{-/-}$tTreg cells were treated with inflammatory cytokines and lipopolysaccharide (LPS). Similar to those reported, tTregs displayed variable sensitivity to different inflammatory cytokines in vitro, shown by reduction in the Foxp3 protein levels (Supplementary Fig. 6a). No difference in inflammatory cytokine-induced Foxp3 downregulation was observed between WT and Dtx $1^{-/-}$tTregs (Supplementary Fig. 6a).

In the hypoxic or inflammatory tissues, HIF- $1 \alpha$ is one of the few proteins suggested to destabilize Foxp3 by binding Foxp 3 and stimulating the ubiquitination of Foxp3, leading to reduction in Treg population ${ }^{32}$. We identified an antagonism between DTX1 and HIF- $1 \alpha$, observing that expression of increasing amounts of DTX1 resulted in decreased HIF-1 $\alpha$ protein levels (Fig. 5a). 
a

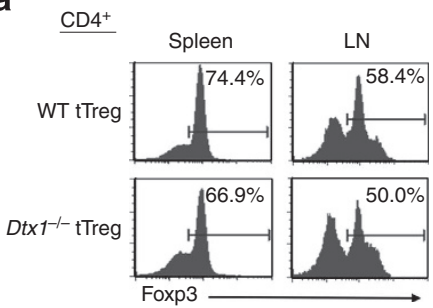

C
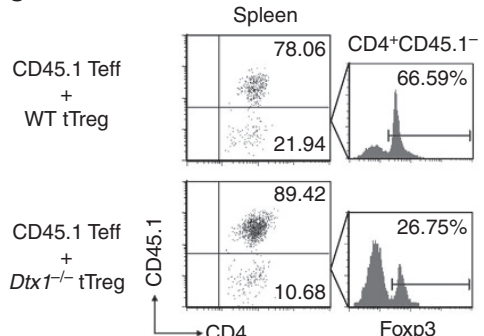

b
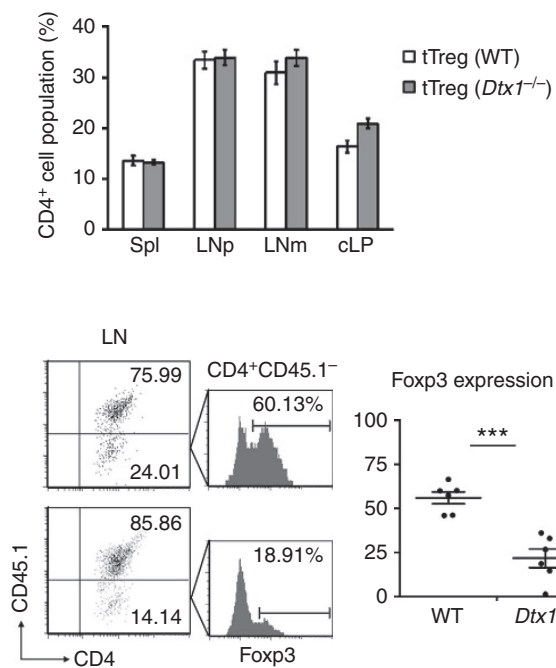

Foxp3 expression (\%)

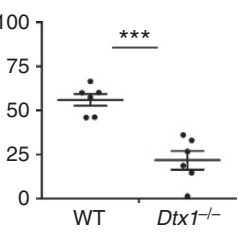

Figure 4 | Co-transfer of Dtx $\mathbf{1}^{-/}$- tTregs with effector T cells leads to Foxp3 downregulation. (a) DTX1 deficiency did not affect the Foxp3 ${ }^{+}$population when tTregs were transferred alone. We administered $1 \times 10^{5}$ tTreg cells from WT and Dtx $1^{-/-}$mice into Rag $1^{-/-}$mice. Spleen and lymph nodes were isolated 1 week later, and the fraction of Foxp3 ${ }^{+}$cells in CD4 ${ }^{+}$T cells was determined. (b) A comparable CD4 ${ }^{+}$population in mice that received WT or Dtx $1^{-/-}$tTregs. Rag $1^{-/-}$mice were adoptively transferred with WT or Dtx $1^{-/-} \mathrm{CD} 4{ }^{+} \mathrm{CD} 25^{+}$tTreg cells. Spleen, peripheral lymph nodes (LNp), mesenteric lymph nodes $(\mathrm{LNm})$ and colonic lamina propria $(\mathrm{cLP})$ were isolated from the recipient mice a week later. Frequencies of $\mathrm{CD} 4^{+} \mathrm{tTreg}$ cells were analysed by flow cytometry. (c) Diminished Foxp3 ${ }^{+}$population from Dtx1 $1^{-/-}$tTregs adoptively transferred with $\mathrm{CD} 4^{+} \mathrm{CD} 25^{-}$cells. $\mathrm{CD} 4{ }^{+} \mathrm{CD} 25^{-}$ T cells from CD45.1 ${ }^{+}$mice were co-transferred with $1 \times 10^{5} \mathrm{WT}$ or Dtx $1^{-/-}$tTreg cells $\left(\mathrm{CD} 45.2^{+}\right)$into Rag $1^{-/-}$mice. Spleen and lymph nodes were isolated 1 week later, and the fraction of Foxp3 ${ }^{+}$cells in the CD4 ${ }^{+} \mathrm{CD} 45.1^{-}$T-cell population was determined. The percentage of Foxp3 ${ }^{+}$cells from spleen and lymph nodes in WT and $D t \times 1^{-/-} \mathrm{CD} 4{ }^{+} \mathrm{CD} 45.1^{-}$T cells is compared from three pair of mice (right panel). ${ }^{\star \star \star} P<0.001$ (paired t-test).

The exposure of DO11.10 T cells to hypoxic conditions upregulated HIF- $1 \alpha$ levels, whereas co-expression of DTX1 greatly decreased the protein half-life of HIF-1 $\alpha$ (Fig. 5b). DTX1-mediated downregulation of HIF-1 $\alpha$ was prevented by treatment with proteasome inhibitor MG132 (Fig. 5c), but not by chloroquine (Fig. 5d) in DO11.10 T cells. Deletion of the RF domain of DTX1 attenuated the ability of DTX1 to promote HIF$1 \alpha$ destabilization (Fig. 5e), indicating a critical role of the RF domain of DTX1 in the downregulation of HIF- $1 \alpha$.

We further detected an interaction of DTX1 with HIF- $1 \alpha$. Immunoprecipitation of HIF- $1 \alpha$ brought down DTX1 in 293T cells (Fig. 5f). The interaction between DTX1 and HIF- $1 \alpha$ was independent of the RF of DTX1, as shown by the association of HIF-1 $\alpha$ with DTX1 $\Delta$ RF (Fig. 5f). The N-terminal WWE domain, in contrast, was required for the interaction between HIF- $1 \alpha$ and DTX1 (Fig. 5f). No interaction between DTX1 and Foxp3, however, was detected (Supplementary Fig. 6b). Despite the binding of DTX1 to HIF- $1 \alpha$, DTX1 did not directly induce the ubiquitination of HIF-1 $\alpha$, as illustrated by in vitro ubiquitination analysis (Supplementary Fig. 7). The stability of HIF-1 $\alpha$ is regulated by prolyl hydroxylase domain protein (PHD)-mediated hydroxylation at Pro402 and Pro564, located in the $\mathrm{O}_{2}$-dependent degradation domain (ODD) region ${ }^{46}$. Knockdown of PHD2 prevented DTX1-induced HIF- $1 \alpha$ degradation in DO11.10 T cells (Fig. $5 \mathrm{~g}$ ), suggesting that DTX1-induced HIF- $1 \alpha$ downregulation is mediated by a PHD2-dependent pathway. MG132 restored HIF-1 $\alpha$ in normoxic T cells (Fig. 5 c), whereas DTX1 deficiency decreased the proline hydroxylation of HIF-1 $\alpha$ in MG132-treated Jurkat T cells (Fig. 5h). Prolyl hydroxylated HIF- $1 \alpha$ is recognized by the von Hippel-Lindau (VHL)-containing E3 complex and ubiquitinated for proteasome degradation ${ }^{46}$. By using the induction of HIF- $1 \alpha$ in normal T cells by TCR/CD28 ligation under normoxic conditions, we found that DTX1 deficiency decreased HIF- $1 \alpha$ ubiquitination in $\mathrm{CD} 4{ }^{+} \mathrm{T}$ cells activated through CD3/CD28 (Fig. 5i). We also observed that CD3/CD28induced HIF-1 $\alpha$ expression was increased in Dtx1 ${ }^{-1-}$ iTreg cells relative to WT iTreg cells (Fig. 5j). DTX1 did not affect the protein stability of PHD2 and VHL (Supplementary Fig. 8). We further found an association between DTX1 and PHD2 (Supplementary Fig. 9a). DTX1, but not DTX1 $\Delta$ RF, inhibited the oligomerization of PHD2 (Supplementary Fig. 9b). How the suppression of PHD2 oligomerization by DTX1 leads to HIF-1 $\alpha$ degradation is being delineated. Together, these results suggest that DTX1 promotes HIF- $1 \alpha$ degradation by binding to HIF- $1 \alpha$ and increasing PHD2-mediated proline hydroxylation and the subsequent ubiquitination of HIF- $1 \alpha$ in T cells.

DTX1 increases Foxp3 levels by antagonizing HIF-1 $\alpha$. We confirmed previous reports showing overexpression of HIF- $1 \alpha$ resulted in a decrease in the levels of Foxp3 (Fig. 6a). In contrast, DTX1 expression led to an elevation of Foxp3 protein contents in 293T cells (Supplementary Fig. 6c). Hypoxia-induced HIF-1 $\alpha$ upregulation was accompanied by a reduction in Foxp3 protein, whereas the expression of DTX1 prevented hypoxia-induced Foxp3 downregulation in DO11.10 T cells (Fig. 6b). We also examined the effect of hypoxia treatment on Foxp3 protein levels in tTregs. Foxp3 contents were comparable between control and Dtx $1^{-9}$ tTregs incubated with IL-2 under normoxic conditions (Fig. 6c). HIF-1 $\alpha$ was induced in tTreg cells when switched to hypoxic conditions. DTX1 deficiency increased hypoxia-mediated HIF- $1 \alpha$ upregulation in tTregs, with a concomitant decrease in Foxp3 (Fig. 6c). Together, these results suggest a protective effect of DTX1 against HIF- $1 \alpha$-mediated Foxp3 instability.

If the failure of $D t x 1^{-/}$Tregs to inhibit effector T cells in vivo (Figs 2 and 3) were due to HIF-1 $\alpha$-mediated Foxp3 downregulation, we hypothesized that the additional deletion of HIF- $1 \alpha$ should rescue the in vivo expression of Foxp 3 and the 
a

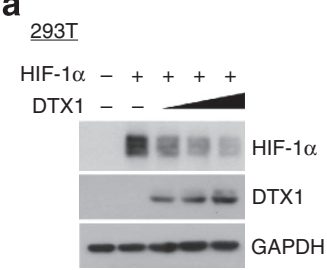

d

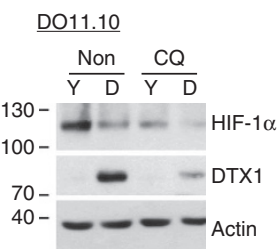

g

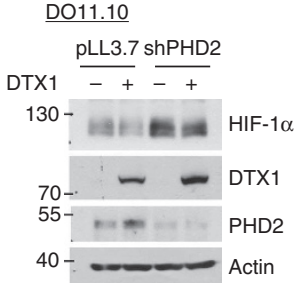

i

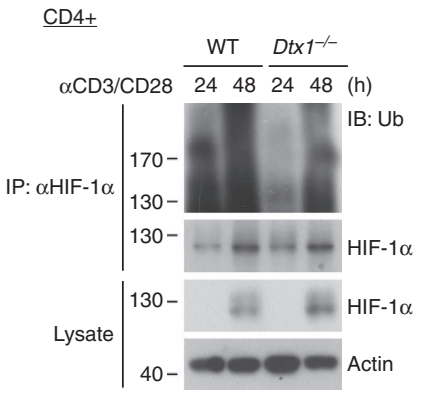

b

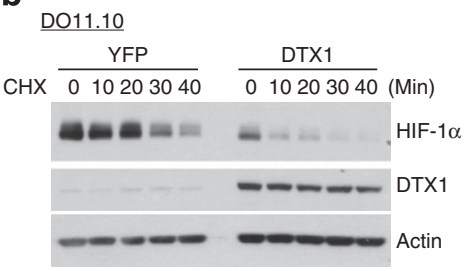

e

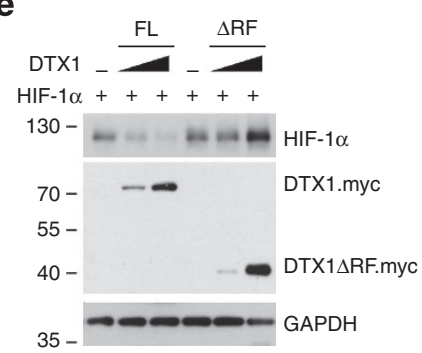

h

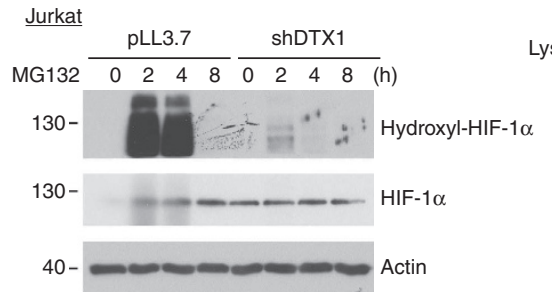

j

f
C

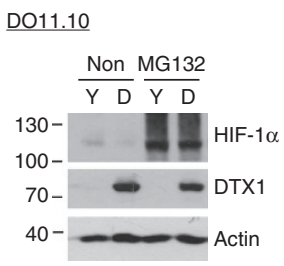

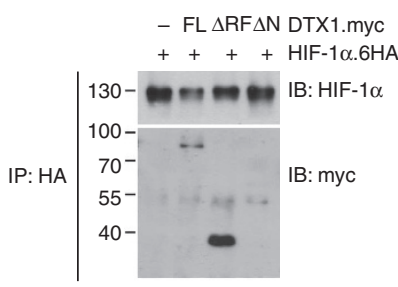

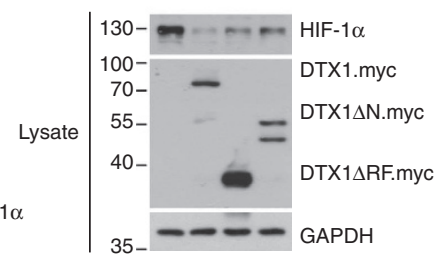

Figure 5 | DTX1 promotes HIF-1 $\alpha$ downregulation. (a) DTX1 promotes HIF- $1 \alpha$ downregulation. 293T cells were transfected with HIF-1 $\alpha$ and DTX1 (0.5, 1 and $2 \mu \mathrm{g}$ ), and cellular levels of HIF-1 $\alpha$ were determined $48 \mathrm{~h}$ later. (b) DTX1 decreases the stability of HIF- $1 \alpha$ protein in T cells. Control and DTX1-expressing D011.10 T cells were incubated in hypoxic conditions $\left(1.1 \% \mathrm{O}_{2}\right)$ for $24 \mathrm{~h}$. Cells were then treated with cycloheximide (CHX), and the amounts of HIF- $1 \alpha$ and DTX1 monitored. (c,d) DTX1-induced HIF-1 $\alpha$ degradation in T cells is proteasome dependent. YFP control and DTX1-expressing DO11.10 cells were incubated in hypoxic conditions for $4 \mathrm{~h}$, in the presence or absence of $10 \mu \mathrm{M} \mathrm{MG132}$ (c) or $50 \mathrm{nM}$ chloroquine (d), and the levels of HIF-1 $\alpha$ and DTX1 analysed. (e) The RING finger domain is required for DTX1 to promote HIF- $1 \alpha$ downregulation. HIF-1 $\alpha$ was co-expressed with DTX1 (FL) or DTX1 $1 \mathrm{RF}$ in 293T cells, and the levels of HIF-1 $\alpha$, DTX1 or DTX1 $\Delta$ RF were analysed. (f) Interaction between DTX1 and HIF- $1 \alpha$. 293T cells were transfected with DTX1(FL), DTX1 $1 \Delta$ RF or DTX1 $\Delta \mathrm{N}$, and HIF-1 $1 \alpha-6 \mathrm{HA}$. The cell lysates were immunoprecipitated using anti-HA, and were analysed with anti-Myc and anti-HIF- $1 \alpha$. $\Delta \mathrm{N}$, $\mathrm{N}$-terminal WWE domain deletion. (g) PHD2 knockdown attenuates DTX1-mediated HIF-1 $\alpha$ downregulation. Control (pLL3.7) and PHD2-knocked down D011.10 cells with or without DTX1 overexpression were incubated in hypoxic conditions for $4 \mathrm{~h}$, and the contents of HIF-1 $\alpha$, DTX1 and PHD2 were determined. (h) DTX1-KD increases HIF-1 $\alpha$ proline hydroxylation. Jurkat cells were treated with MG132 and the extent of proline hydroxylation on HIF-1 $\alpha$ was determined. (i) Decreased HIF-1 $\alpha$ ubiquitination in Dtx $1^{-/-}$T cells stimulated by CD3/CD28. WT and Cd4 ${ }^{\text {Cre }}$ Dtx $7^{f / f}$ CD4 ${ }^{+}$T cells were stimulated by CD3/CD28, and total cell lysates isolated at 24 and $48 \mathrm{~h}$ after activation. Cell lysates were precipitated with anti-HIF- $1 \alpha$, and the extent of ubiquitination was determined by anti-Ub. (j) Increased HIF- $1 \alpha$ expression in Dtx $1^{-/-}$iTreg cells stimulated by CD3/CD28. Foxp $3^{\text {Cre }}$ and Foxp $3^{\text {Cre }} D t x 7^{f / f} \mathrm{iTreg}$ cells were generated as described in Fig. 3b. iTreg cells were subjected to activation by CD3/CD28 in normoxic conditions, and HIF- $1 \alpha$ expression was monitored. All experiments were independently repeated three $(\mathbf{a}-\mathbf{g})$ or two $(\mathbf{h}-\mathbf{j})$ times. GAPDH, glyceraldehyde 3-phosphate dehydrogenase; HA, hemagglutinin tag; IB, immunoblotting; IP, immunoprecipitation.

function of $D t x 1^{-/-}$Tregs. We bred Cd4 ${ }^{C r e} H i f 1 a^{f / f}$ mice with $C d 4^{C r e}$ Dtxilf $1^{f / f}$ mice to produce mice with Dtx1 ${ }^{-/-}$Hifla $a^{-/-}$ $\mathrm{T}$ cells and crossed Foxp3 ${ }^{C r e}$ Hifla $/$ f/f mice with Foxp3 ${ }^{C r e}$ Dtx $1^{f / f}$ mice to generate Dtx $1^{-/-}$Hifla ${ }^{-/-}$Treg cells (Fig. 6d). CD4 ${ }^{+}$ $\mathrm{CD} 25^{+} \mathrm{T}$ cells were isolated from $\mathrm{Cd} 4^{\mathrm{Cre}}$ mice (Supplementary Fig. 10), whereas $\mathrm{RFP}^{+}$(tTreg) cells were sorted from Foxp $3^{\text {Cre }}$ mice, and these tTreg cells were co-transferred with CD45.1 ${ }^{+}$ effector $\mathrm{T}$ cells into Rag1 ${ }^{-/}$mice. Foxp3 levels were not decreased in WT and Hifla ${ }^{-/-}$tTreg cells 1 week after transfer, in contrast to reduced Foxp3 expression in Dtx $1^{-/-}$tTregs at the same time point (Fig. 6e and Supplementary Fig. 11). The deletion of Hifla restored the expression of Foxp3 in Dtx $1^{-/-}$ 
a

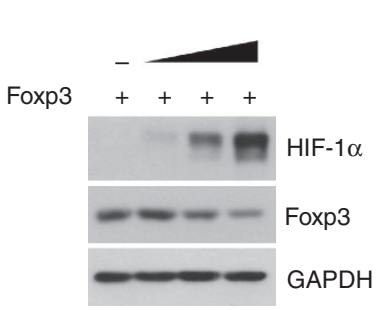

b

\section{$\underline{D 011.10}$}

DTX1 - - + + $\mathrm{NH} \mathrm{N} \mathrm{H}$

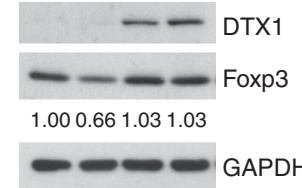

c

Foxp3 relative expression (\%)

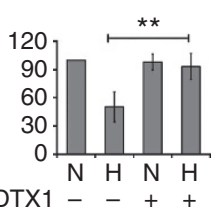

$\underline{\mathrm{t} T r e g}$

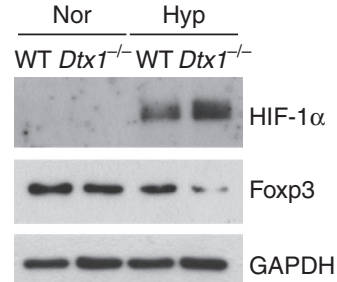

d

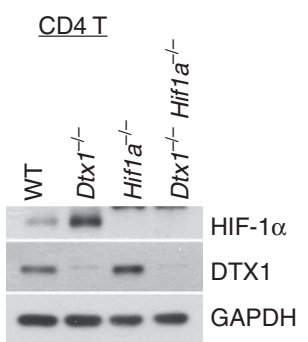

e

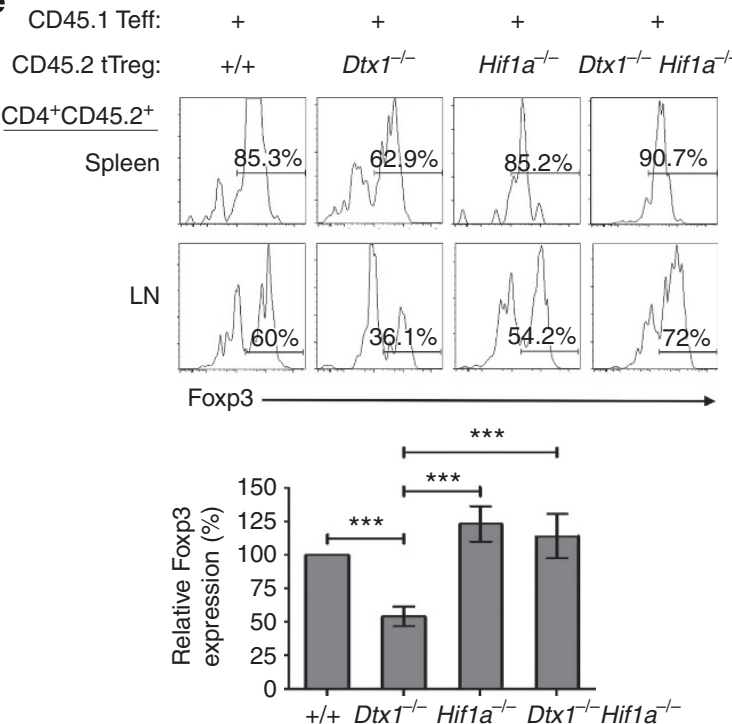

g

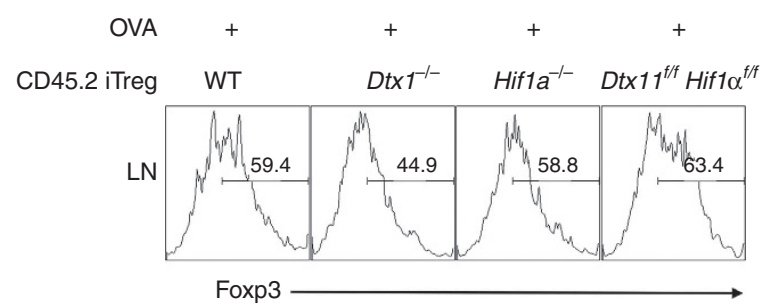

h
IL-4

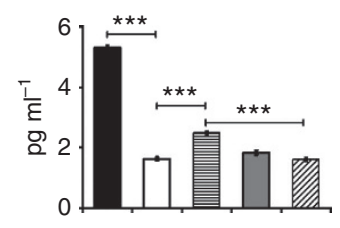

IL-6

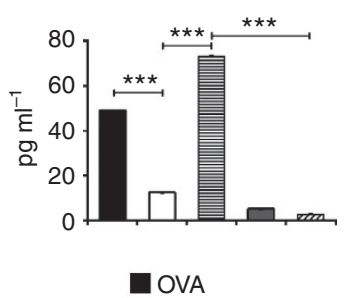

OVA

$\square$ OVA+iTreg (WT)

目 OVA+iTreg $\left(D t x 1^{-/-}\right)$

$\square$ OVA+iTreg $\left(\right.$ Hif1 $\left.^{-/-}\right)$

OVA+iTreg ((Dtx1 $\left.1^{-/-} H_{i f 1} a^{-/-}\right)$

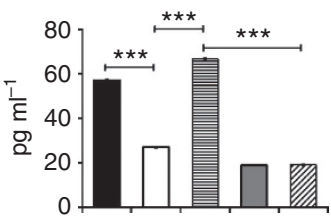

IL-13

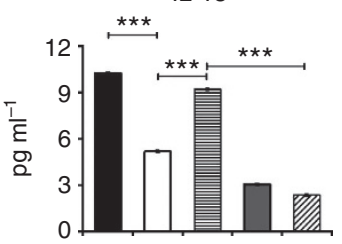

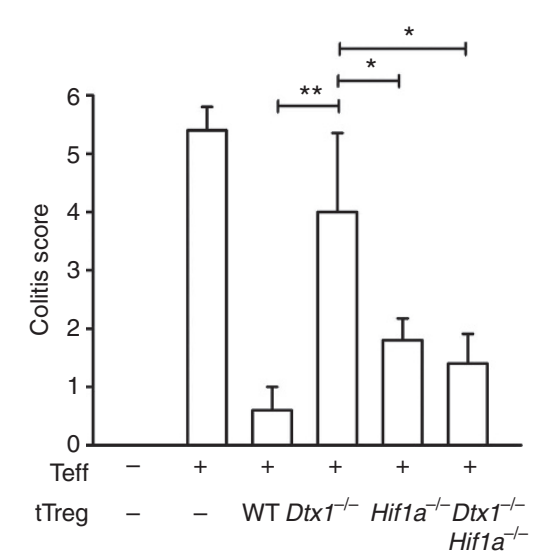

Figure 6 | DTX1 increases Foxp3 stability through HIF-1 $\alpha$ downregulation. (a) HIF-1 $\alpha$ promotes Foxp3 degradation. 293T cells were transfected with Foxp3, ubiquitin and HIF-1 $\alpha$, and cellular levels of Foxp3 determined. (b) DTX1 protects Foxp3 from HIF-1 $\alpha$-induced degradation. Foxp3-expressing DO11.10 cells were transfected with or without DTX1. Cells were incubated in normoxic $(\mathrm{N})$ conditions for $16 \mathrm{~h}$ and kept at $\mathrm{N}$ conditions or switched to hypoxic ( $\mathrm{H}$ ) conditions for $4 \mathrm{~h}$, and levels of DTX1 and Foxp3 were analysed. Right panel, quantification from three independent experiments. (c) Increased HIF- $1 \alpha$ induction and decreased Foxp3 levels in hypoxia-treated Dtx $1^{-/-}$tTreg cells. Control and Dtx $1^{-/-}$tTregs were activated by CD3/CD28 plus IL-2 in N or

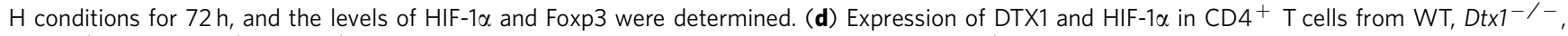

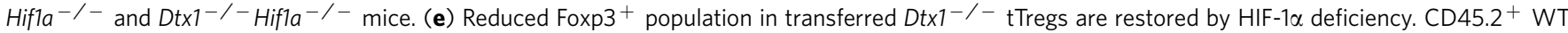

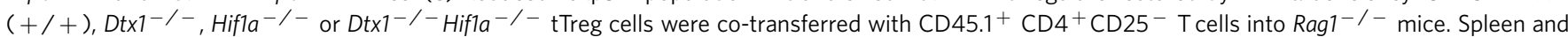
lymph nodes were isolated 1 week later, and the frequency of Foxp3 ${ }^{+}$cells in the $\mathrm{CD} 4{ }^{+} \mathrm{CD} 45.2^{+}$T-cell population was determined. Bottom panel, splenic Foxp $3^{+}$cells from three mice each group. The percentage of $+/+$was set as $100 \%$. (f) Hifla knockout enables Dtx $1^{-/-} \mathrm{tTregs}$ to inhibit colitis. Colitis

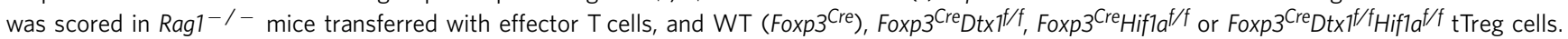

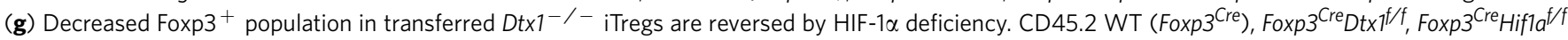
or Foxp3 ${ }^{\mathrm{Cre}} \mathrm{Dtx} 7^{f / f} \mathrm{Hif1a^{f/f }}$ iTreg cells were administered to CD45.1 B6 mice, followed by ovalbumin immunization. The transferred CD45.2 iTreg cells were isolated from lymph nodes of mice killed at day 25, and the frequency of Foxp3 ${ }^{+}$cells was determined. Data are representative of three mice in each group. (h) HIF-1 $\alpha$ deficiency restores the in vivo inhibitory activity of Dtx $1^{-/-}$iTreg cells. B6 mice were treated with WT, Dtx $1^{-/-}\left(C d 4^{C r e} D t x 7^{f / f}\right)$,

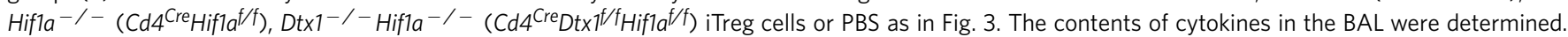
$\mathrm{GAPDH}$, glyceraldehyde 3-phosphate dehydrogenase. BALF, bronchoalveolar lavage fluid. ${ }^{\star} P<0.05,{ }^{\star \star} P<0.01,{ }^{\star \star \star} P<0.001$ for paired $\mathrm{t}$-test. 
tTregs in vivo, suggesting that HIF- $1 \alpha$ accounts for the Foxp3 downregulation in DTX1-deficient Tregs. Consistent with normal levels of Foxp3 in the recovered Tregs, Hifla-knockout reestablished the ability of Dtx $1^{-/}$tTregs to repress $\mathrm{CD} 4^{+}$ CD25 ${ }^{-}$T cell-induced colitis in Rag1 ${ }^{-1-}$ mice as determined by colitis score readout (Fig. 6f), body weight loss and intestinal morphology (Supplementary Fig. 12). Histological analysis revealed that Dtx1 $1^{-/-} \mathrm{Hifla}^{-/-}$tTregs efficiently inhibited $\mathrm{CD} 4{ }^{+} \mathrm{CD} 25^{-} \mathrm{T}$ cell-induced mononuclear cell infiltrate, crypt damage and goblet cell damage in $R a g 1^{-1-}$ mice, in contrast to the ineffectiveness of Dtx $1^{-}$- tTregs (Supplementary Fig. 13).

We further examined the effect of HIF-1 $\alpha$-knockout in the suppressive activity of Dtx $1^{-/-}$iTregs. Reduction in Foxp3 expression was observed in Dtx $1^{-/-}$iTreg cells isolated from OVA-sensitized mice, and was reversed by additional Hifla-knockout (Fig. 6g). Hifla $a^{-/-}$iTregs were as effective as WT iTregs in the inhibition of allergen-induced production of IL-5, IL-6 and IL-13 (Fig. 6h). The attenuated ability of Dt $x 1^{-/}-$iTregs to suppress the allergenic IL-5, IL-6 and IL-13 secretion was rescued by Hifla knockout, shown by the full inhibitory activity of Dtx $1^{-/-} H_{i f 1} a^{-/-}$iTregs in the same assay. Lung tissue sections revealed that the extensive OVAinduced mononuclear cell infiltration was effectively prevented by administration of Dtx $1^{-/-} H$ ifla $a^{-/-}$iTregs (Supplementary Fig. 14). Together, these results indicate that deficiency in HIF- $1 \alpha$ corrected the defects of Dtx $1^{-/-}$iTregs in inhibition of allergic inflammation. Therefore, part of the DTX1-mediated protective effects on Foxp3 expression in vivo is through antagonizing HIF- $1 \alpha$.

\section{Discussion}

$\mathrm{T}$ cell-specific deletion of Dtx1 results in increased T-cell activation and autoantibody generation ${ }^{40}$. In the present study, we further found that Treg-specific deletion of Dtx1 led to enhanced T-cell activation and elevated autoantibody production (Fig. 1), suggesting that the presence of DTX1 in Tregs is also required for maintenance of full T-cell immune tolerance. The phenotypes of Foxp $3^{C r e} D t x 1^{f / f}$ mice were not as profound as those in $C d 4^{C r e} D t x 1^{f / f}$ mice. The increase in T-cell proliferation was modest in Foxp $3^{C r e} D$ tx $1^{f / f} \mathrm{~T}$ cells (Fig. 1a) relative to a twofold enhanced $\mathrm{T}$-cell proliferation in $C d 4^{C r e} D t x 1^{f / f} \mathrm{~T}$ cells ${ }^{40}$. In addition, the elevated anti-histone antibodies in $C d 4^{C r e} D t x 1^{f / f}$ mice were not detectable in Foxp $3^{C r e} D t x 1^{f / f}$ mice (Supplementary Fig. 1f). Therefore, the phenotypes previously observed in $C d 4^{C r e}$ Dtx $1^{f / f}$ mice $^{40}$ are likely a combinatory consequence of the loss of T-cell anergy and impairment of Treg activity.

The normal development of tTregs in $D t x 1^{-}$- mice and the comparable Foxp3 levels in Dtx $1^{-}$- iTregs indicate that DTX1 does not directly participate in the expression of Foxp3. In addition, DTX1 deficiency did not affect the expression of Tregassociated molecules including CD25, CTLA-4 and GITR, which are also transcriptional targets of Foxp3. Unlike transcription factors like NFAT that are associated with Foxp3 for the expression of targets such as Il2ra and Ctla4 (ref. 47), DTX1 is apparently not involved in the expression of genes through coordination with Foxp3.

We also demonstrated that Treg-specific deficiency in DTX1 impaired the suppressive function of tTregs and iTregs in vivo, but did not affect the ability of Tregs to inhibit $\mathrm{T}$ effector cell activation in vitro. Recent studies have shown that deficiency in STAT3 or Ubc13 does not affect the frequency of tTregs, the expression level of Foxp3 or the in vitro suppressive activity of Tregs, but profoundly alters the in vivo suppressive activity of tTregs $^{27,48}$. For Treg function, various mechanisms have been identified for the Treg-mediated inhibitory mechanism in vitro.
However, whether these mechanisms also operate in vivo remains unclear $^{7}$. Our results thus provide additional evidence that the in vivo function of Tregs could be regulated by mechanisms not detectable in vitro.

We further found that the defective in vivo suppressive activity by $D t \times 1^{-/-}$Treg cells could be attributed to the instability of Foxp3 protein. The expression and epigenetic control of the Foxp3 gene have been well characterized ${ }^{17}$. In contrast, the regulation on the Foxp3 protein stability is incompletely understood. Loss of Foxp3 in Tregs leads to generation of autoreactive effector $\mathrm{T}$ cells ${ }^{29,30}$. Two ubiquitin-modifying enzymes, Stub1 and USP7, act directly on Foxp3 protein stability. LPS and proinflammatory cytokines induce expression of E3 ubiquitin ligase Stub1, whereas Stub1 binds Foxp3 and induces Foxp3 K48-polyubiquitination and degradation in an Hsp70-dependent manner ${ }^{28}$. In contrast, the binding of deubiquitinase USP7 to Foxp3 promotes the removal of polyubiquitination from Foxp3 and increases Foxp3 protein levels ${ }^{31}$. In addition, non-ubiquitin-modifying enzymes like HIF$1 \alpha$ bind Foxp 3 and promote Foxp3 degradation in PHD 2dependent processes ${ }^{32}$, whereas Sirtuin 1 interacts with Foxp3 and promotes Foxp3 ubiquitination and degradation by deacetylation of Foxp3 (ref. 49).

In the present study, we demonstrated a new mechanism: the E3 ligase DTX1 can increase the in vivo stability of Foxp3 by degradation of HIF- $1 \alpha$ protein. DTX1 did not bind Foxp3 (Supplementary Fig. 6b), yet DTX1 increased Foxp3 stability (Supplementary Fig. 6c). Unlike Stub1 (ref. 28), DTX1 is not involved in LPS-induced destabilization of Foxp3 protein in Tregs (Supplementary Fig. 6a). DTX1 protected Foxp3 from hypoxiainduced Foxp3 downregulation (Fig. $6 \mathrm{~b}, \mathrm{c}$ ) by promoting HIF-1 $\alpha$ destabilization. We found that DTX1 bound and promoted HIF$1 \alpha$ degradation in a PHD2-dependent process (Fig. 5e-g), leading to a profound reduction of the HIF-1 $\alpha$ protein half-life (Fig. 5b). Notably, DTX1 did not directly promote the ubiquitination of HIF-1 $\alpha$ (Supplementary Fig. 7). Instead, DTX1 increased the proline hydroxylation of HIF-1 $\alpha$. The exact molecular processes underlying the binding of DTX1 to HIF-1 $\alpha$ and that lead to accelerated HIF- $1 \alpha$ degradation are currently being examined. Our results suggest that DTX1-HIF- $1 \alpha$-Foxp3 represents a pathway different from those of inflammatory cytokines in the regulation of the protein stability of Foxp3.

DTX1 belongs to a family of NFAT-dependent E3 ligases that includes Cbl-b, ITCH and GRAIL and that are involved in T-cell anergy ${ }^{50}$. Similar to DTX1, deficiency in ITCH and GRAIL does not affect the development of tTregs and iTregs or expression of Foxp3 (refs 51,52). The development of tTregs and suppressive function of $\mathrm{Cblb}^{-/-}$Tregs are also normal ${ }^{53}$. Notably, these E3 ligases regulate the functional integrity of Tregs cells using different mechanisms. Itch ${ }^{-/}-$Treg cells secrete excess Th2 cytokines that lead to chronic T-cell activation, skin lesions and antigen-induced airway hypersensitivity ${ }^{51}$. GRAIL knockout in Tregs leads to attenuated suppressive function ${ }^{52}$. Cbl-b-deficiency is accompanied by elevated PI-3 kinase activation, reduced nuclear presence of Foxo3 and Foxo1, and attenuated Foxp3 expression in Tregs ${ }^{54}$. Together, DTX1, Cbl-b, ITCH and GRAIL represent a class of E3 ligases that are not only essential for T-cell anergy, but also are required for the functional integrity of Tregs.

An opposing role of HIF- $1 \alpha$ in Foxp 3 regulation has also been reported in which HIF- $1 \alpha$ transactivates the Foxp3 promoter and stimulates Foxp3 expression ${ }^{55}$. In the present study, the stability of Foxp3 was assessed in Treg cells isolated from the spleen and lymph nodes, representing peripheral fully differentiated Tregs. Our study therefore may have excluded the developmental stage of Tregs in which HIF- $1 \alpha$ is reported to participate in Foxp3 expression $^{55}$. However, we found that Hifla $a^{-/-}$tTregs retained 
the ability to inhibit colitis (Supplementary Fig. 13), in contrast to the impaired suppressive function of Hifla- $1-$ tTregs in the same model reported by Clambey et al..$^{55}$ We noticed that Hifla $a^{-1}$ tTregs were less effective than WT tTregs in the readout of colitis score (Fig. 6f), but not in the histology analysis (Supplementary Fig. 13). There was likely difference between Hif $1 a^{-1-}$ tTregs and WT tTregs. Further studies will be required to determine the exact window to detect the effects of HIF- $1 \alpha$ knockout in the inhibitory activity of tTregs.

HIF- $1 \alpha$ is induced by inflammatory stimuli, cytokines and growth factors even in normoxic conditions ${ }^{56}$. HIF- $1 \alpha$ is expressed in $\mathrm{T}$ cells that have infiltrated inflammatory tissues ${ }^{57}$. HIF-1 $\alpha$ interacts with Foxp3 and promotes Foxp3 degradation ${ }^{32}$. Blocking the binding of HIF- $1 \alpha$ to Foxp3 increases Foxp3 levels in Tregs, resulting in enhanced Treg suppressive activities ${ }^{33}$. HIF$1 \alpha$ has been shown to destabilize Foxp3 protein in fully differentiated Tregs in hypoxic or inflammatory states in vitro ${ }^{25,28}$. This evidence supports the possibility that HIF- $1 \alpha$ also mediates the downregulation of Foxp3 in Tregs in a physiological inflammatory environment. We found that DTX1 was able to increase Foxp3 stability through HIF-1 $\alpha$ downregulation. In $D t x 1^{-/-}$iTregs, HIF-1 $\alpha$ induced by TCR stimulation was clearly increased (Fig. 5j), indicating an association between the dysfunctional $D t x 1^{-/-}$Tregs and upregulated HIF-1 $\alpha$. In addition, knockout of HIF- $1 \alpha$ in Dtx $1^{-1-}$ tTreg and Dtx $1^{-/-}$iTreg cells restored Foxp3 expression and its suppressive activity in vivo (Fig. 6e-h and Supplementary Figs 11-14). Our results therefore suggest that the function of Tregs in vivo requires factors like DTX1 to sustain stable expression of Foxp3 under hypoxic or inflammatory conditions. DTX1 represents another level of control of Treg function by regulating the protein stability of Foxp3 against the destabilizing effect of HIF- $1 \alpha$ in vivo. Notably, Tregs are present at high frequency in tumour tissues and are associated with suppression of effector $\mathrm{T}$ cells within the tumour microenviroment ${ }^{58,59}$. Tumours contain hypoxic regions, with increased HIF-1 $\alpha$ protein levels ${ }^{46}$. Given the ability of HIF- $1 \alpha$ protein to degrade Foxp3 (refs 32,33), we propose that DTX1 may also contribute to the stability of tumour-infiltrated Tregs by antagonizing HIF- $1 \alpha$.

Tregs are one of the major components in immune tolerance maintenance ${ }^{3-7}$. Administration of Tregs to restore immune tolerance has been explored as a potential therapeutic approach in transplantation, autoimmune diseases and allergy ${ }^{8-21}$. The present study illustrates a new level of regulation on the stability of Tregs by antagonizing HIF- $1 \alpha$. It may be noted that DTX1 is unlikely the only protein that participates in the downregulation of HIF- $1 \alpha$. Given the diverse proinflammatory stimuli Tregs may encounter in their lifespan, DTX1 may coordinate with several stabilizing factors to confer full protection on Foxp3 protein expression in Tregs. Identification of these stabilizing factors and further characterization of the molecular mechanism underlying the Foxp3-stabilizing effect of DTX1 will help provide a full molecular picture on the physiological regulation of Tregs, as well as establish the basis for the application of Tregs in immunotherapy.

\footnotetext{
Methods

Reagents. Mouse deltex $1 \mathrm{cDNA}^{36}$ was a gift from Dr Hideyuki Okano (Keiko University, Tokyo, Japan). HIF- $1 \alpha$ and HIF- $1 \alpha(\Delta \mathrm{ODD})$ were obtained from Dr Kou-Juey Wu (National Yang-Ming University, Taipei, Taiwan). Polyclonal anti-DTX1 antibody was generated by immunizing rabbits with recombinant DTX1. OVA, alum, anti-FLAG (M2, 1;1,000) and the periodic acid-Schiff (PAS) staining system were purchased from Sigma. The antibodies against glyceraldehyde 3-phosphate dehydrogenase $(6 \mathrm{C} 5,1: 5,000)$ and $\mathrm{His}(\mathrm{H}-3,1: 1,000)$ were obtained from Santa Cruz Biotech. Fluorescein isothiocyanate (FITC)-labelled streptavidin was purchased from Invitrogen/Caltag. Anti-IFN- $\gamma$ (XMG1.2, 1:100), anti-IL-17
}

(18H10, 1:100), anti-CD103 (M290, 1:100), anti-HIF-1 $\alpha$ (54/HIF-1 $\alpha, 1: 1,000)$, anti-VHL (Ig32, 1:500) and Cytometric Bead Array were obtained from BD-Bioscience. Anti-HIF-1 $\alpha$ (1:1,000) was purchased from Cayman. FITC- or PE-conjugated anti-CD25 (PC61.5.3, 1:100), anti-LAG3 (C9B7W, 1;100), antiROR- $\gamma \mathrm{t}$ (B2D, 1:2,000), anti-Foxp3 (eBio7979, 1:500), FITC-conjugated anti-Foxp3 (FJK-16s, 1:100), anti-CD44 (IM7, 1:100), anti-CD45.1 (A20, 1:100) and PE-conjugated anti-FR4 (12A5, 1:100) were purchased from eBioscience. FITC- or PE-conjugated anti-CD4 (GK1.5, 1:100), PE-conjugated anti-CD152 (CTLA-4; UC10-4B9, 1:100), PE-conjugated anti-GITR (YGITR765, 1:100), anti-CD62L (Mel-14, 1:100), anti-CD45.2 (104, 1:100), anti-CCR4 (2G12, 1:100), anti-CCR5 (HM-CCR5, 1:100) and anti-CCR6 (29-2L17, 1:100) were obtained from BioLegend. Anti-Myc (9B11, 1:1,000) and anti-hydroxyl HIF-1 $\alpha$ (Pro564, 1:1,000) were purchased from Cell Signaling. Anti-PHD2 (NB100-137, 1:2,000) was obtained from Novus. Biotinylated anti-TGF- $\beta 1$ (1:200) and anti-IL-12 p35 (27537) were obtained from R\&D. Anti- $\beta$-tubulin $(1: 2,000)$ was obtained from Upstate. Anti-lamin B1 (1:1,000) was purchased from Zymed. Horseradish peroxidase-conjugated secondary antibodies and ECL were obtained from Amersham Bioscience. The reverse transcription-PCR primers were as follows: Dtx1: forward 5' -CAAAGCCATCTACGGGGA-3', reverse 5'-TGGCCATGGC CTCAGAAAC-3'; Foxp3: forward 5'-AGCTGCAGCTGCCTACAG-3', reverse 5'-CCAGCAGTGGGTAGGATC-3'; Ccr4: forward 5'-ATCCTGAAGGACTTCA AGCTCCA-3', reverse 5'-AGGTCTGTGCAAGATCGTTTCATGG-3'; Ccr6: forward $5^{\prime}$-CCTCACATTCTTAGGACTGGAGC-3' ${ }^{\prime}$, reverse $5^{\prime}$-GGCAATCAGA GCTCTCGGA-3'; Ccr7: forward 5'-ATGCTGGCTATGAGTTTC-3', reverse 5'-GCTGCTATTGGTGATGTT-3'; Ebi3: forward 5'-AGCAGCAGCCTCCTAG CCT-3', reverse 5'-ACGCCTTCCGGAGGGTC-3'; Foxo1: forward 5'-ACGAACT CGGAGGCTCCTTAGACAC- $3^{\prime}$, reverse $5^{\prime}$-GACTGGAGGTGGTCGAGTTGGA CTG-3'; Foxo3a, forward 5'-ATGGGCCACGATAAGT- $3^{\prime}$, reverse $5^{\prime}$-CAGTAA CAGTCCGCCT-3'; Gzmb: forward 5'-CTCCACGTGCTTTCACCAAA- $3^{\prime}$, reverse 5'-AGGATCCATGTTGCTTCTGTAGTTAG-3'; I kzf4: forward 5'-CCAAGTCC CTGAGTGGTTGT-3', reverse 5'-TTATCCAGGAGCCGTTCATC-3'.

Mice. The Dtx $1^{f / f}$ mice and Dtx $1^{-/-}$mice $\left(D t x 1^{f / f}\right.$ EIIa-Cre, mice with systemic deletion of Dtxl) were previously described ${ }^{40}$. Rag1 ${ }^{-1-}$ mice, NOD/ShiLt$\mathrm{Tg}$ (Foxp3 $3^{\mathrm{EGFP} / \mathrm{Cre}}$ )1 1Jbs/J mice (also known as NOD.Foxp3-Cre) ${ }^{41}$ and B6.129Hifla ${ }^{\text {tm } 3 R s j o} / \mathrm{J}\left(\text { Hifl } 1 a^{f / f}\right)^{60}$ were obtained from Jackson Laboratories. NOD.Foxp3Cre mice were back-crossed to C57BL6 mice for at least eight generations. Foxp $3^{R F P-C r e}$ transgenic ((C57BL/6-Tg(Foxp3-RFP,-Cre)1Narl) mice were generated by National Laboratory Animal Center, Taiwan, with the construct similar to that in Foxp $3^{E G F P-C r e}$ mouse. No difference was observed between Foxp $3^{R F P-C r e}$ mouse and Foxp $3^{G F P-C r e}$ mouse in Treg-specific knockout of DTX1, and Foxp $3^{\mathrm{Cre}}$ mouse was used to represent either one. Cd4-Cre mice were obtained from Taconic Farms. All mice used were 8-10 weeks old. For colitis experiments, only female donors and recipients mice were used. For other in vivo experiments, sex-matched male and female mice were used. Both male and female mice were used for in vitro experiments. All mouse experiments were conducted with the approval of the Experimental Animal Committee, Academia Sinica.

Cell culture and transfection. Jurkat cells (clone E6-1, TIB-152) were obtained from American Type Culture Collection. DO11.10 cells were I-A ${ }^{\mathrm{d}}$-restricted, OVA-specific T-cell hybridomas ${ }^{61}$. T cells were cultured in RPMI media with $10 \%$ fetal calf serum (both from GIBCO), $10 \mathrm{mM}$ glutamine, $100 \mathrm{U} \mathrm{ml}^{-1}$ penicillin, $100 \mathrm{U} \mathrm{ml}^{-1}$ streptomycin and $2 \times 10^{-5} \mathrm{M} 2$ mercaptoethanol (ME). DMEM was used instead of RPMI in the culture of 293T cells.

For the transfection of $293 \mathrm{~T}$ cells, $1 \times 10^{6} 293 \mathrm{~T}$ cells were seeded overnight. Plasmid DNA (1-4 $\mu \mathrm{g})$ and OmicsFect in vitro Transfection Reagent $(2-8 \mu \mathrm{l}$, in a ratio of $1 \mu \mathrm{g}$ DNA to $2 \mu \mathrm{l}$ reagent; Omics Biotechnology) were diluted separately in $250 \mu \mathrm{l}$ serum-free DMEM medium. The diluents were mixed slowly, set at room temperature for $15 \mathrm{~min}$ and were then added to 293T cells. 293T cells were analysed $24 \mathrm{~h}$ later. Transfection of Jurkat and DO11.10 T cells was conducted by electroporation on a Neon Transfection System (MP-100 Microporator, Invitrogen). A total of $1 \times 10^{7} \mathrm{~T}$ cells were washed twice with PBS and resuspended in $100 \mu \mathrm{l}$ resuspension R buffer (Invitrogen). A measure of 500 pmole short interfering RNA or $10 \mu \mathrm{g}$ plasmid DNA were added to cells, and T cells were electroporated at $1,700 \mathrm{~V}, 30 \mathrm{~ms}, 1$ pulse. T cells were then resuspended in $10 \mathrm{ml}$ antibiotic-free complete RPMI medium, and cultured for $24-72 \mathrm{~h}$ before further analysis.

For retroviral infection of T cells, Foxp3 or DTX1 were subcloned into pGCIRES-YFP, a gift from Dr Gina Costa (Stanford University). Retroviruses were produced using Phoenix-Eco cells (gifts of Dr Garry P Nolan, Stanford University) ${ }^{39}$. DO11.10 T cells were mixed with retroviruses-containing supernatants with polybrene $\left(1 \mathrm{mg} \mathrm{ml}^{-1}\right)$, and spin-infected at 1,900 r.p.m. for $45 \mathrm{~min}$ at $30^{\circ} \mathrm{C}$. Two days after infection, YFP-expressing DO11.10 cells were isolated by sorting on FACSVantage SE (Becton Dickinson).

Cell lysates and immunoblots. For the preparation of whole-cell lysates, cells were lysed by whole-cell extract buffer (25 mM HEPES, pH 7.7, $300 \mathrm{mM} \mathrm{NaCl}$, $0.1 \%$ Triton X-100, $1.5 \mathrm{mM} \mathrm{MgCl}_{2}, 0.2 \mathrm{mM}$ EDTA, $0.1 \mathrm{mM} \mathrm{Na}_{3} \mathrm{VO}_{4}, 50 \mathrm{mM} \mathrm{NaF}$, $0.5 \mathrm{mM}$ dithiothreitol and $10 \%$ glycerol) on ice for $30 \mathrm{~min}$. Debris was removed by 
centrifuge on a Eppendoff microfuge (13,200 r.p.m., $30 \mathrm{~min}, 4^{\circ} \mathrm{C}$ ), and protein concentrations in the supernatants quantitated by Bio-Rad protein assay.

For immunoprecipitation, whole-cell lysates were incubated with $1 \mu \mathrm{g}$ specific antibody overnight at $4{ }^{\circ} \mathrm{C}$. This was followed by incubation with Protein G Mag Sepharose ( $10 \mu \mathrm{l}$; GE Healthcare) for $2 \mathrm{~h}$ at $4{ }^{\circ} \mathrm{C}$. The beads were washed five times and analysed by SDS-polyacrylamide gel electrophoresis (SDS-PAGE).

For immunoblots, lysates or immunoprecipitates resolved by SDS-PAGE were transferred to polyvinylidene difluoride membrane (Millipore) with transfer buffer (30 mM Tris, $250 \mathrm{mM}$ glycine, $1 \mathrm{mM}$ EDTA, $20 \%$ methanol) at $4{ }^{\circ} \mathrm{C}$ for $2 \mathrm{~h}$ at $400 \mathrm{~mA}$. Membranes were blocked with $5 \%$ non-fat milk in $0.1 \%$ TBST $(10 \mathrm{mM}$ Tris- $\mathrm{HCl} \mathrm{pH} 8.0,150 \mathrm{mM} \mathrm{NaCl}, 0.1 \%$ Tween-20) at room temperature for $1 \mathrm{~h}$. The membrane was then incubated with primary antibodies overnight at $4{ }^{\circ} \mathrm{C}$. After washing, the membrane was incubated with horseradish peroxidase-conjugated secondary antibodies in blocking buffer for $1.5 \mathrm{~h}$ at room temperature. After washing three times, membranes were developed using ECL western blot detection reagents (GE Healthcare), and signals detected by X-ray film. Immunoblot images have been cropped for presentation. Full-size images are presented in Supplementary Figs 15-17.

Regulatory T cells. Treg cells from splenocytes were purified using a magneticactivated cell sorting (MACS) $\mathrm{CD} 4{ }^{+} \mathrm{CD} 25^{+}$Regulatory T Cell Isolation Kit (Miltenyi Biotech) or by fluorescence-activated cell sorting (FACS). The intracellular staining of Foxp3 was conducted on paraformaldehyde-fixed splenocytes prelabelled for CD4 and CD25. Cells were then permeabilized with $0.2 \%$ saponin and stained with FITC-conjugated anti-Foxp3 (1:100, eBioscience). IL-10 and TGF- $\beta$ levels were measured in supernatants from tTreg cells stimulated with anti-CD3 $\left(5 \mu \mathrm{g} \mathrm{ml}^{-1}\right)$, anti-CD28 $\left(2 \mu \mathrm{g} \mathrm{ml}^{-1}\right)$ and IL-2 $\left(50 \mathrm{U} \mathrm{ml}^{-1}\right)$ for 3 days by a mouse IL-10 DuoSet ELISA System (R\&D) and a TGF- $\beta$ OptEIA Set (BD Bioscience), respectively. For the staining of surface TGF- $\beta 1, \mathrm{CD} 4{ }^{+} \mathrm{CD} 25^{+} \mathrm{T}$ cells were stimulated with plate-bound anti-CD3/anti-CD28 and IL-2 $\left(50 \mathrm{U} \mathrm{ml}^{-1}\right)$ for $96 \mathrm{~h}$, fixed with $2 \%$ paraformaldehyde and labelled sequentially with biotinylated antiTGF- $\beta 1(1: 100)$ and FITC-streptavidin.

Induced Treg (iTreg) cells were generated from CD4 ${ }^{+} \mathrm{CD} 25^{-} \mathrm{T}$ cells by treating with immobilized anti-CD3 $\left(5 \mu \mathrm{g} \mathrm{ml}^{-1}\right)$ and anti-CD28 $\left(1 \mu \mathrm{g} \mathrm{ml}^{-1}\right)$ in the presence of TGF- $\beta\left(5 \mathrm{ng} \mathrm{ml}^{-1}\right)$ for $5-7$ days. CD4 ${ }^{+} \mathrm{CD} 25^{+}$cells were isolated by MACS at day 5 and used for in vitro and in vivo suppression analysis. For expression of Treg-associated molecules, iTreg cells after 6-day treatment were first stained with antibodies specific for CD103, CTLA-4, FR4, GITR, LAG3 or TGF- $\beta$, followed by secondary antibody. Cells were then permeabilized, stained with FITCconjugated anti-Foxp3 and the expression of each marker in the Foxp3 ${ }^{+}$ population was analysed by FACS

In vitro suppressive assay of Tregs. $\mathrm{CD} 4{ }^{+} \mathrm{CD} 25^{-}$cells were placed into roundbottom 96-well plates at $1 \times 10^{5}$ cells per well; each well also contained anti-CD3 $\left(1 \mu \mathrm{g} \mathrm{ml}^{-1}\right), 3 \times 10^{5} \gamma$-irradiated $\mathrm{T}$ cell-depleted splenic cells, and $1.25,2.5,5$ or $10 \times 10^{4} \mathrm{CD} 4{ }^{+} \mathrm{CD} 25^{+}$Treg cells. Cells were incubated for $72 \mathrm{~h}$. $\left[{ }^{3} \mathrm{H}\right]$ thymidine was then added, and cells were harvested $8 \mathrm{~h}$ later for thymidine incorporation determination. IFN- $\gamma$ production was measured $40 \mathrm{~h}$ after TCR stimulation by ELISA.

Induction of colitis in Rag1 ${ }^{-/}-$mice. $\mathrm{CD}^{+}{ }^{+} \mathrm{CD} 25^{-} \mathrm{T}$ cells $\left(4 \times 10^{5}\right)$ from female mice were administered by intraperitoneal injection into female RAG1 ${ }^{-1}$ mice (8- to 10 -week-old) with or without $1 \times 10^{5}$ tTregs from female mice. Colitis was assessed weekly. The score for wasting was as follows: 0 , no wasting; 1 for up to $10 \%$ initial body weight loss and 2 for $>10 \%$ initial body weight loss. Rectal prolapse was scored as 0 for absence and 1 for presence. Diarrhoea was scored as 0 for absence, 1 for soft stool and 2 for watery/bloody stool. Hunching/bristled fur/ skin lesions were scored as 0 for absence and 1 for presence. At 7 weeks after T-cell transfer, mice were killed and blood was removed by cardiac perfusion with PBS. Colons were removed, cleaned by PBS, fixed in $4 \%$ paraformaldehyde and then embedded in paraffin. Sections were stained with haematoxylin and eosin or PAS staining system.

Allergen-induced airway inflammation. C57/BL6 mice (8- to 10-week-old) were intravenously injected with or without $2.5 \times 10^{6}$ iTreg cells or PBS on day 0 , and sensitized with two intraperitoneal doses of $50 \mu \mathrm{g}$ OVA in $2 \mathrm{mg}$ alum solution ${ }^{62}$ on day 1 and day 14 . Mice were challenged daily for $30 \mathrm{~min}$ with OVA by placing them in a chamber where an aerosolized solution of $1 \%$ OVA in saline $(0.9 \% \mathrm{NaCl})$ was generated by a Nebulizer 646 in aerosol therapy system (DeVilbliss) from days 21 to 24 . On day 25 , mice were killed, perfused with PBS and lungs were fixed with $4 \%$ PFA followed by staining with haematoxylin and eosin and PAS.

In vitro ubiquitination assay. Bovine ubiquitin, rabbit rhUBE1 (E1) and UbcH5c (E2) were purchased from BostonBiodem. The in vitro ubiquitination reaction mixture contained ubiquitin $(1 \mu \mathrm{g})$, E1 $(0.2 \mu \mathrm{g})$, E2 $(0.2 \mu \mathrm{g})$, His-Deltex1 $(0.2 \mu \mathrm{g})$, His-Deltex1 $\Delta \mathrm{RF}(0.2 \mu \mathrm{g})$, GST-HIF- $1 \alpha(0.5 \mu \mathrm{g})$ or GST-MEKK1(C) $(0.5 \mu \mathrm{g})$, as indicated, in $30 \mu \mathrm{l}$ of reaction buffer $(25 \mathrm{mM}$ Tris, $\mathrm{pH} 7.5,50 \mathrm{mM} \mathrm{NaCl}, 10 \mathrm{mM}$ $\mathrm{MgCl}_{2}, 2 \mathrm{mM}$ ATP, $0.5 \mathrm{mM}$ dithiothreitol). The reaction mixture was incubated at $30{ }^{\circ} \mathrm{C}$ for $1 \mathrm{~h}$. Ubiquitin and ubiquitin-associated proteins were pulled down from the reaction mixture by incubation with $1 \mu \mathrm{g}$ of anti-ubiquitin (Millipore) overnight at $4{ }^{\circ} \mathrm{C}$, followed by incubation with Protein G Mag Sepharose $(20 \mu \mathrm{l})$ at $4{ }^{\circ} \mathrm{C}$ for additional $2 \mathrm{~h}$. Mag Sepharose was then washed five times with reaction buffer without ATP, and resolved on SDS-PAGE. The amount of ubiquitin-associated protein was determined by blotting with anti-GST (1:5,000, GE).

\section{References}

1. Sakaguchi, S., Sakaguchi, N., Asano, M., Itoh, M. \& Toda, M. Immunologic selftolerance maintained by activated $\mathrm{T}$ cells expressing IL-2 receptor a-chains (CD25): Breakdown of a single mechanism of self-toleracne causes various autoimmune diseases. J. Immunol. 155, 1151-1164 (1995).

2. Suri-Payer, E., Amar, A. Z., Thornton, A. M. \& Shevach, E. M. CD4 ${ }^{+}$CD $25{ }^{+}$ $\mathrm{T}$ cells inhibit both the induction and effector function of autoreactive $\mathrm{T}$ cells and represent a unique lineage of immunoregulatory cells. J. Immunol. 160, 1212-1218 (1998).

3. Sakaguchi, S., Yamaguchi, T., Nomura, T. \& Ono, M. Regulatory T cells and immune tolerance. Cell 133, 775-787 (2008).

4. Littman, D. R. \& Rudensky, A. Y. Th17 and regulatory T cells in mediating and restraining inflammation. Cell 140, 845-858 (2010).

5. Shevach, E. M. Biological functions of regulatory T cells. Adv. Immunol. 112 137-175 (2012).

6. von Boehmer, H. Mechanisms of suppression by suppressor T cells. Nat. Immunol. 6, 338-344 (2005).

7. Shevach, E. M. Mechanisms of Foxp $3^{+}$T regulatory cell-mediated suppression. Immunity 30, 636-645 (2009).

8. McHugh, R. S. et al. CD $4{ }^{+} \mathrm{CD} 25^{+}$immunoregulatory T cells: gene expression analysis reveals a functional role for the glucocorticoid-induced TNF receptor. Immunity 16, 311-323 (2002).

9. Huang, C. T. et al. Role of LAG-3 in regulatory T cells. Immunity 21, 503-513 (2004).

10. Yamaguchi, T. et al. Control of immune responses by antigen-specific regulatory T cells expressing the folate receptor. Immunity 27, 145-159 (2007)

11. Curotto de Lafaille, M. A. \& Lafaille, J. J. Natural and adaptive Foxp $3^{+}$ regulatory T cells: more of the same or a division of labor? Immunity $\mathbf{3 0}$ 626-635 (2009).

12. Feuerer, M., Hill, J. A., Mathis, D. \& Benoist, C. Foxp3 ${ }^{+}$regulatory T cells: differentiation, specification, subphenotypes. Nat. Immunol. 10, 689-695 (2009).

13. Hori, S., Nomura, T. \& Sakaguchi, S. Control of regulatory T cell development by the transcription factor Foxp3. Science 299, 1057-1061 (2003).

14. Fontenot, J. D., Gavin, M. A. \& Rudensky, A. Y. Foxp3 programs the development and function of $\mathrm{CD} 4{ }^{+} \mathrm{CD} 25^{+}$regulatory T cells. Nat. Immunol. 4, 330-336 (2003).

15. Williams, L. M. \& Rudensky, A. Y. Maintenance of the Foxp3-dependent developmental program in mature regulatory $\mathrm{T}$ cells requires continued expression of Foxp3. Nat. Immunol. 8, 277-284 (2007).

16. Wan, Y. Y. \& Flavell, R. A. Regulatory T-cell functions are subverted and converted owing to attenuated Foxp3 expression. Nature 445, 766-770 (2007)

17. Ohkura, N., Kitagawa, Y. \& Sakaguchi, S. Development and maintenance of regulatory T cells. Immunity 38, 414-423 (2013).

18. Miyara, M., Wing, K. \& Sakaguchi, S. Therapeutic approaches to allergy and autoimmunity based on FoxP3 + regulatory T-cell activation and expansion. J. Allergy Clin. Immunol. 123, 749-755 (2009).

19. Riley, J. L., June, C. H. \& Blazar, B. R. Human T regulatory cell therapy: take a billion or so and call me in the morning. Immunity 30, 656-665 (2009).

20. Tang, Q., Bluestone, J. A. \& Kang, S. M. CD4 ${ }^{+}$Foxp3 ${ }^{+}$regulatory T cell therapy in transplantation. J. Mol. Cell Biol. 4, 11-21 (2012).

21. Cobbold, S. P. \& Waldmann, H. Regulatory cells and transplantation tolerance. Cold Spring Harb. Perspect. Med 3, a015545 (2013).

22. Sakaguchi, S., Vignali, D. A., Rudensky, A. Y., Niec, R. E. \& Waldmann, H. The plasticity and stability of regulatory T cells. Nat. Rev. Immunol. 13, 461-467 (2013).

23. Rubtsov, Y. P. et al. Stability of the regulatory T cell lineage in vivo. Science 329, 1667-1671 (2010).

24. Miyao, T. et al. Plasticity of foxp3 $(+)$ T cells reflects promiscuous foxp3 expression in conventional $\mathrm{T}$ cells but not reprogramming of regulatory $\mathrm{T}$ cells. Immunity 36, 262-275 (2012).

25. Yang, X. O. et al. Molecular antagonism and plasticity of regulatory and inflammatory T cell programs. Immunity 29, 44-56 (2008).

26. Oldenhove, G. et al. Decrease of Foxp3 + Treg cell number and acquisition of effector cell phenotype during lethal infection. Immunity 31, 772-786 (2009).

27. Laurence, A. et al. STAT3 transcription factor promotes instability of tTreg cells and limits generation of iTreg cells during acute murine graft-versus-host disease. Immunity 37, 209-222 (2012).

28. Chen, Z. et al. The ubiquitin ligase stub1 negatively modulates regulatory $\mathrm{T}$ cell suppressive activity by promoting degradation of the transcription factor foxp 3 . Immunity 39, 272-285 (2013). 
29. Zhou, X. et al. Instability of the transcription factor Foxp3 leads to the generation of pathogenic memory T cells in vivo. Nat. Immunol. 10, 1000-1007 (2009).

30. Komatsu, N. et al. Pathogenic conversion of Foxp3 $(+)$ T cells into TH17 cells in autoimmune arthritis. Nat. Med. 20, 62-68 (2014).

31. van Loosdregt, J. et al. Stabilization of the transcription factor Foxp3 by the deubiquitinase USP7 increases Treg-cell-suppressive capacity. Immunity 39, 259-271 (2013).

32. Dang, E. V. et al. Control of $\mathrm{T}_{\mathrm{H}} 17 /$ Treg balance by hypoxia-inducible factor 1 . Cell 146, 772-784 (2011).

33. Darce, J. et al. An N-terminal mutation of the Foxp3 transcription factor alleviates arthritis but exacerbates diabetes. Immunity 36, 731-741 (2012).

34. McNamee, E. N., Korns Johnson, D., Homann, D. \& Clambey, E. T. Hypoxia and hypoxia-inducible factors as regulators of $\mathrm{T}$ cell development, differentiation, and function. Immunol. Res. 55, 58-70 (2013).

35. Matsuno, K., Diederich, R. J., Go, M. J., Blaumueller, C. M. \& ArtavanisTsakonas, S. DTX acts as a positive regulator of Notch signaling through interactions with the Notch ankyrin repeats. Development 121, 2633-2644 (1995).

36. Kishi, N. et al. Murine homologs of DTX define a novel gene family involved in vertebrate Notch signaling and neurogenesis. Int. J. Dev. Neurosci. 19, 21-35 (2001).

37. Hori, K. et al. Drosophila Deltex mediates suppressor of hairless-independent and late-endosomal activation of Notch signaling. Development 131, 5527-5537 (2004).

38. Hori, K., Sen, A., Kirchhausen, T. \& Artavanis-Tsakonas, S. Synergy between the ESCRT-III complex and Deltex defines a ligand-independent Notch signal. J. Cell. Biol. 195, 1005-1015 (2011).

39. Liu, W. H. \& Lai, M. Z. Deltex regulates T cell activation by targeted degradation of active MEKK1. Mol. Cell. Biol. 25, 1367-1378 (2005).

40. Hsiao, H. W. et al. Deltex1 is a target of transcription factor NFAT that promotes T cell anergy. Immunity 31, 72-83 (2009).

41. Zhou, X. et al. Selective miRNA disruption in Treg cells leads to uncontrolled autoimmunity. J. Exp. Med. 205, 1983-1991 (2008).

42. Huehn, J., Polansky, J. K. \& Hamann, A. Epigenetic control of FOXP3 expression: the key to a stable regulatory T-cell lineage? Nat. Rev. Immunol. 9, 83-89 (2009).

43. Lal, G. \& Bromberg, J. S. Epigenetic mechanisms of regulation of Foxp3 expression. Blood 114, 3727-3235 (2009).

44. Mucida, D. et al. Reciprocal TH17 and regulatory T cell differentiation mediated by retinoic acid. Science 317, 256-260 (2007).

45. Hill, J. A. et al. Retinoic acid enhances Foxp3 induction indirectly by relieving inhibition from CD4 + CD44hi cells. Immunity 29, 758-770 (2008).

46. Semenza, G. L. Hypoxia-inducible factors in physiology and medicine. Cell 148, 399-408 (2012)

47. $\mathrm{Wu}, \mathrm{Y}$. et al. FOXP3 controls regulatory $\mathrm{T}$ cell function through cooperation with NFAT. Cell 126, 375-387 (2006).

48. Chang, J. H. et al. Ubc13 maintains the suppressive function of regulatory $\mathrm{T}$ cells and prevents their conversion into effector-like T cells. Nat. Immunol. 13, 481-490 (2012).

49. van Loosdregt, J. et al. Rapid temporal control of Foxp3 protein degradation by sirtuin-1. PLoS ONE 6, e19047 (2011).

50. Heissmeyer, V. et al. Calcineurin imposes T cell unresponsiveness through targeted proteolysis of signaling proteins. Nat. Immunol. 5, 255-265 (2004).

51. Jin, H. S., Park, Y., Elly, C. \& Liu, Y. C. Itch expression by Treg cells controls Th2 inflammatory responses. J. Clin. Invest. 123, 4923-4934 (2013).

52. Nurieva, R. I. et al. The E3 ubiquitin ligase GRAIL regulates T cell tolerance and regulatory $\mathrm{T}$ cell function by mediating $\mathrm{T}$ cell receptor-CD3 degradation. Immunity 32, 670-680 (2010).

53. Wohlfert, E. A., Callahan, M. K. \& Clark, R. B. Resistance to CD $4^{+}$CD $25^{+}$ regulatory $\mathrm{T}$ cells and TGF-beta in Cbl-b ${ }^{-1-}$ mice. J. Immunol. 173, 1059-1065 (2004).
54. Harada, Y. et al. Transcription factors Foxo3a and Foxol couple the E3 ligase Cbl-b to the induction of Foxp3 expression in induced regulatory T cells. J. Exp. Med. 207, 1381-1391 (2010).

55. Clambey, E. T. et al. Hypoxia-inducible factor-1 alpha-dependent induction of FoxP3 drives regulatory $\mathrm{T}$-cell abundance and function during inflammatory hypoxia of the mucosa. Proc. Natl Acad. Sci. USA 109, E2784-E2793 (2012).

56. Hellwig-Burgel, T., Rutkowski, K., Metzen, E., Fandrey, J. \& Jelkmann, W. Interleukin- $1 \beta$ and tumor necrosis factor- $\alpha$ stimulate DNA binding of hypoxia-inducible factor-1. Blood 94, 1561-1567 (1999).

57. Makino, Y. et al. Hypoxia-inducible factor regulates survival of antigen receptor driven T cells. J. Immunol. 171, 6534-6540 (2003).

58. Zou, W. Regulatory T cells, tumour immunity and immunotherapy. Nat. Rev. Immunol. 6, 295-307 (2006).

59. Nishikawa, H. \& Sakaguchi, S. Regulatory T cells in cancer immunotherapy. Curr. Opin. Immunol. 27C, 1-7 (2014)

60. Ryan, H. E. et al. Hypoxia-inducible factor-1alpha is a positive factor in solid tumor growth. Cancer Res. 60, 4010-4015 (2000).

61. White, J., Haskins, K. M., Marrack, P. \& Kappler, J. Use of I region-restricted, antigen-specific $\mathrm{T}$ cell hybridomas to produce idiotypically specific antireceptor antibodies. J. Immunol. 130, 1033-1037 (1983).

62. Pichavant, M., Goya, S., Hamelmann, E., Gelfand, E. W. \& Umetsu, D. T. Animal models of airway sensitization. Curr. Protoc. Immunol 15.18.1-15.18.19 (2007).

\section{Acknowledgements}

We thank Drs Hideyuki Okano, Gina Costa, Garry Nolan and John Kung for providing key materials used in this study, National Laboratory Animal Center at Taiwan for C57BL/6-Tg(Foxp3-RFP,-Cre)1Narl mice, Yamin Lin and the FACS Core Facility of the Institute of Molecular Biology, Academia Sinica for cell sorting, and Dr AndreAna Peña for editing the manuscript. This work was supported by grant 102-2321-B001-045 from National Science Council, Taiwan, and Academia Sinica Investigator Award from Academia Sinica, Taiwan.

\section{Author contributions}

M.-Z.L. conceived of the idea, designed and supervised the experiments, and wrote the manuscript, H.-W.H., T.-S.H. and W.-H.L. performed in vitro and in vivo Treg analysis, W.-C.H., T.-F.C. and Y.-J.W. performed selected immunoblots, S.-T.J. generated Foxp $3^{\text {RFP-Cre }}$ transgenic mice.

\section{Additional information}

Supplementary Information accompanies this paper at http://www.nature.com/ naturecommunications.

Competing financial interests: The authors declare no competing financial interests.

Reprints and permission information is available online at http://npg.nature.com/ reprintsandpermissions.

How to cite this article: Hsiao, H.-W. et al. Deltex1 antagonizes HIF- $1 \alpha$ and sustains the stability of regulatory T cells in vivo. Nat. Commun. 6:6353 doi: 10.1038/ncomms7353 (2015).

This work is licensed under a Creative Commons Attribution 4.0 International License. The images or other third party material in this article are included in the article's Creative Commons license, unless indicated otherwise in the credit line; if the material is not included under the Creative Commons license, users will need to obtain permission from the license holder to reproduce the material. To view a copy of this license, visit http://creativecommons.org/licenses/by/4.0/ 